\title{
Simulation of crack propagation in anisotropic structures using the boundary element shape sensitivities and optimisation techniques
}

Dol:

10.1016/j.enganabound.2011.03.006

\section{Document Version}

Accepted author manuscript

Link to publication record in Manchester Research Explorer

Citation for published version (APA):

Tafreshi, A. (2011). Simulation of crack propagation in anisotropic structures using the boundary element shape sensitivities and optimisation techniques. Engineering Analysis with Boundary Elements, 35(8), 984-995.

https://doi.org/10.1016/j.enganabound.2011.03.006

Published in:

Engineering Analysis with Boundary Elements

\section{Citing this paper}

Please note that where the full-text provided on Manchester Research Explorer is the Author Accepted Manuscript or Proof version this may differ from the final Published version. If citing, it is advised that you check and use the publisher's definitive version.

\section{General rights}

Copyright and moral rights for the publications made accessible in the Research Explorer are retained by the authors and/or other copyright owners and it is a condition of accessing publications that users recognise and abide by the legal requirements associated with these rights.

\section{Takedown policy}

If you believe that this document breaches copyright please refer to the University of Manchester's Takedown Procedures [http://man.ac.uk/04Y6Bo] or contact uml.scholarlycommunications@manchester.ac.uk providing relevant details, so we can investigate your claim.

\section{OPEN ACCESS}




\title{
Simulation of Crack Propagation in Anisotropic Structures Using the Boundary Element Shape Sensitivities and Optimization Techniques
}

\author{
Azam Tafreshi \\ atafreshi@manchester.ac.uk \\ School of Mechanical, Aerospace and Civil Engineering, University of Manchester, Oxford Road, \\ Manchester, M13 9PL, England, UK
}

Using the boundary element shape sensitivities of multi-region domains coupled with an optimization algorithm and an automatic mesh generator, the crack kink angle and propagation path in anisotropic elastic solids are predicted. The maximum strain energy release rate criterion, best suited for the composite structures, has been employed. In contrast to the J-integral method, which would require the computation of stresses and strains at a series of internal points, here by direct differentiation of the structural response the strain energy release rates at the existing crack tip and new cracks for the period of crack growth are determined. The length of each kinked crack is treated as the shape design variable. The shape variable is then associated with the coordinates of a series of boundary nodes located on the new crack surface. Thus, the relevant velocity terms are applied together in the sensitivity analysis with respect to that variable to determine the energy release rate, which is the derivative of the total strain energy with respect to the crack length extension. Wherever possible the results are compared with the existing experimental, analytical and/or numerical results reported in the literature, in which good agreement is observed. It is shown that the present method is computationally more accurate and efficient. Two example problems with different anisotropic material properties are presented to validate the applications of this formulation. The results show that material anisotropy has a profound influence on the crack propagation of composites.

\section{Introduction}

Laminated composites are gaining importance in aerospace structural applications because of their attractive performance characteristics such as high strength-to-weight ratios, high stiffness-to-weight ratios, superior fatigue properties, and high corrosion resistance. Aircraft structures are prone to cracking due to wear and tear, especially when they are used beyond their fatigue life. The tensile strengths of composite laminates are significantly reduced when stress concentrations such as cracks and cutouts are present. The Finite Element(FE) and Boundary Element(BE) are the most extensively used methods for the design and strength analysis of anisotropic structures, particularly, for solving fracture mechanics problems. 
However, the BEM, being a boundary-oriented technique, can overcome a number of the difficulties associated with its main rival, the FEM. Early contribution to the development of the Boundary Element Method (BEM) for cracked anisotropic plates belongs to Snyder and Cruse [1].

The mixed-mode crack problems in two-dimensional linear elasticity can be characterized by a pair of stress intensity factors (SIF's). For isotropic materials, SIFs have been used to predict fatigue crack growth and fracture. Generally, the most popular method to determine the SIFs of a cracked body is the J-integral method [2]. The J-integral is path-independent for all integral paths surrounding the crack tip. Using this method requires the computation of stresses and strains at a series of internal points around the crack, for evaluation of the pathindependent integrals, which is obviously time consuming.

For elastic problems the $\mathrm{J}_{1}$-integral is the energy release rate per unit extension of the crack. In conjunction with the Finite Element Method (FEM) or BEM, it is possible to use the shape sensitivity analysis to directly evaluate the sensitivities of the total strain energy where the crack length is being treated as the shape variable.

In a recent study by the author [3] the application of the boundary element shape sensitivity for the analysis of two dimensional anisotropic bodies with cracks of arbitrary shapes was presented. The design sensitivity analysis of multi-region domains with anisotropic material properties was carried out by direct differentiation of the structural response. The length of the crack of an arbitrary shape was treated as the shape variable. The shape variable was then associated with the coordinates of a series of boundary nodes located on the crack surfaces. Thus, the relevant velocity terms were applied together in the sensitivity analysis with respect to that variable to determine the derivatives of displacements, stresses and the elastic compliance of the structure with respect to the crack extension. Following the calculation of strain energy release rate (SERR) or the rate of energy released per unit of crack extension using the boundary element shape sensitivities, and using the related material property parameters of a composite material, the SIFs in pure or mixed mode I-II loading conditions were determined. The results showed the advantage of using the boundary element shape sensitivities in fracture mechanics over the J-integral method, both in terms of the computational modeling and numerical accuracy. It was also shown that although the SIF is of fundamental importance in the prediction of brittle failure using linear elastic fracture mechanics, the direct evaluation of the SERR would easily characterize the crack instability of a loaded laminated composite for different fibre orientations. For the cases studied, 
although there was a small variation in the normalized SIFs with respect to the fibre angle, the variation of the SERR with respect to the fibre orientation was more apparent.

In another study on instability analysis of delaminated composite cylindrical shells subject to axial compression, external pressure and bending, either applied individually or in combination [4-6], it was also shown that the SERR was more convenient to use for the prediction of crack growth and fracture of delaminated composite structures.

This paper continues the previous work of the author [3] and presents the application of the boundary element shape sensitivities and optimization techniques for the prediction of the crack kink angle and propagation path of two dimensional anisotropic bodies with cracks of arbitrary shapes.

It is well known that the crack kink direction mainly depends on the crack tip conditions. Various fracture criteria [7] have been established to determine the crack kink angle at which a pre-existing crack will propagate in an isotropic material. The most popular methods are the maximum tangential stress criterion (MTS) [8], the minimum strain energy density criterion (S-criterion) [9-10] and the maximum energy release rate criterion (Max. SERR) [11-12]. It should be noted that the T-criterion [13-14] is suitable for ductile fractures where the Mises elastic-plastic boundary is used near the crack tip.

Obviously, the fracture behaviour of anisotropic materials under mixed mode loading cannot be predicted by the same criteria that are developed for the isotropic materials and, therefore, when using the MTS and S-criterion some modifications must be made to include the effects of anisotropy [15-21].

This paper shows the advantage of using the boundary element shape sensitivities for prediction of the crack growth over other existing methods, both in terms of the computational modelling and numerical accuracy. The maximum SERR criterion which is well suited for both composite and isotropic structures has been employed. Two example problems with anisotropic material properties are presented to validate the applications of this formulation. Wherever possible the results have been compared with the corresponding experimental and analytical results reported in the literature, in which good agreement are observed. It should be noted that most existing methods, for the prediction of crack growth in fibre-reinforced composites rely on calculating the SIFs during the incremental process. However, in Ref.[3] it was shown that in comparison with the SERR, SIFs are less sensitive to the fibre angle. 


\section{Nomenclature}

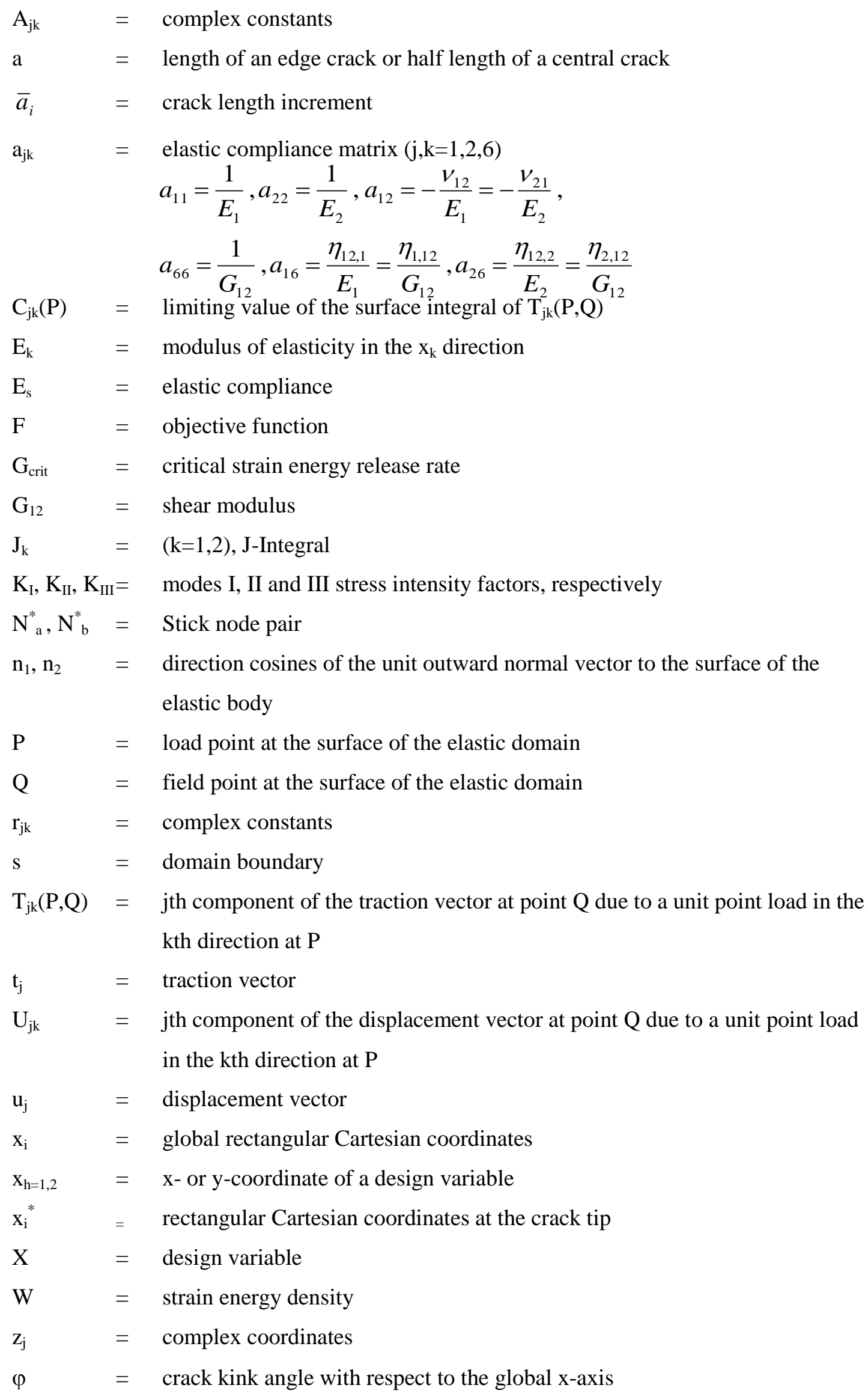




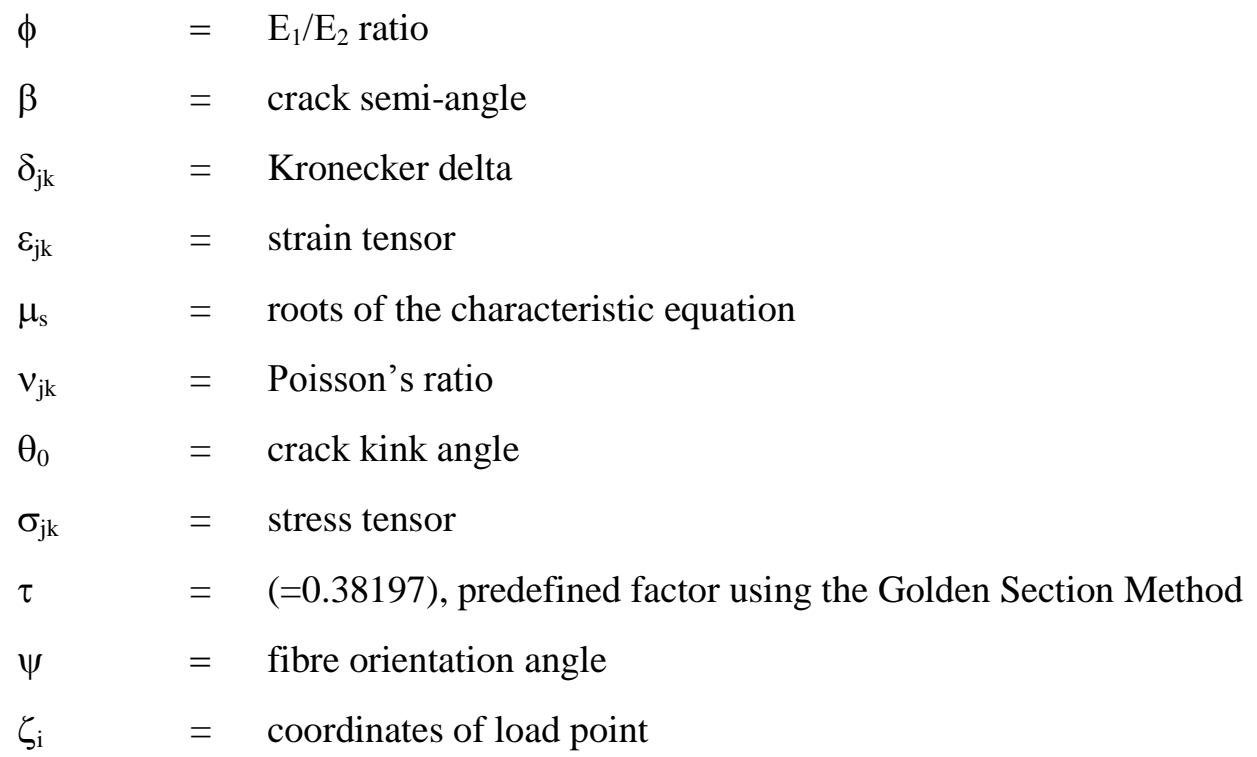

\section{Prediction of the crack kink angle and propagation path}

The SIF is of fundamental importance in the prediction of brittle failure using linear elastic fracture mechanics (LEFM). It is a function of both the cracked geometry and the associated loading. $\mathrm{K}_{\mathrm{I}}$ and $\mathrm{K}_{\mathrm{II}}$ are the Mode I and Mode II SIFs, respectively. They characterise the stress fields in the vicinity of the crack tip with respect to a local Cartesian $\left(\mathrm{x}^{*}{ }_{1}-\mathrm{x}_{2}{ }_{2}\right)$ system which has its origin at the tip of the crack (point B) and is oriented with the angle of $\varphi$ with respect to the global Cartesian system $\left(\mathrm{x}_{1}-\mathrm{x}_{2}\right)$, as shown in Fig.1. If the length of the crack (AB) of arbitrary shape is treated as the shape variable, this shape variable can then be associated with the coordinates of a series of boundary nodes located on the crack surfaces. Thus, the relevant velocity terms are applied together in the sensitivity analysis with respect to that variable to determine the derivatives of displacements, stresses and the elastic compliance of the structure with respect to the crack length extension [3]. The derivative of the elastic compliance is equivalent to the SERR per unit of crack extension or $\mathrm{J}_{1}$ integral. Following the calculation of the SERR, and the related material property parameters of a composite material, the SIFs of the structure in single or mixed mode loading conditions can be determined [3]. Obviously, the application of the boundary element shape sensitivities in crack analysis over the J-integral method is computationally more efficient and accurate.

For a two-dimensional plane stress or plane strain problem subject to mixed mode loading, a crack grows in a non-collinear fashion where the direction of crack extension makes an angle with respect to the existing crack line. This angle is called the crack kink angle or crack initiation angle, designated $\theta_{0}$ in this study. Fig. 2a shows a two-dimensional domain with a side crack of arbitrary shape with the length (a). Assuming the crack is extended along BD, an imaginary boundary along which an incremental crack extension $(\bar{a})$ is assumed to occur. This is due to the fact that crack kinking induces a geometric discontinuity at the crack tip. 
Clearly, the SERR at the tip of the parent crack (B) and the tip of the new kinked $\operatorname{crack}(\mathrm{C})$ are different. Now, if the length of the new crack (BC) is treated as the shape variable, similar to the method explained above, the SERR with respect to the crack extension at point $\mathrm{C}$ can be determined.

Based on the Max. SERR criterion, the crack will grow in such a direction $\left(\theta_{0}\right)$ for which the SERR has a maximum value, which means that at the onset of crack kinking tip $\frac{\partial J_{1}}{\partial \theta}=0$.

Therefore, the prediction of the crack kink angle can be treated as the minimization of the constrained function of one variable, where the objective function $(\mathrm{F})$ and the design variable $(X)$ are the SERR $\left(J_{1}\right)$ and the crack kink angle $\left(\theta_{0}\right)$, respectively. Since at the onset of crack growth the SERR is maximum, the negative value of the SERR will be considered as the objective function. The limits on the variable and the fixed outer boundary can be treated as the geometrical constrains. Several methods are available for numerically solving the onedimensional constrained minimization problem. These can be classified as interpolation and elimination methods [22].

The interpolation procedure involves the evaluation of the objective function at several points and fitting a polynomial to those known points. The minimum of this polynomial is a good estimate to the minimum of the objective function. The advantage of this method is that it requires a few function evaluations. However, for highly nonlinear functions the approximation may be quite poor and cannot be used for discontinuous functions.

The elimination methods can be used for the minimization of even discontinuous functions. This assumes the function is unimodal, so there is no need for continuous derivatives. A unimodal function has only one peak in a given interval. If a function is unimodal in a given range, the interval in which the minimum lies can be narrowed down. The most efficient form of the elimination method is the Golden Section Method (GSM) [22] which has been employed in this study. This method has a good rate of convergence and is very reliable for poorly conditioned problems. In this method it is assumed that lower and upper bounds on the design variable $(\mathrm{X})$ are $\mathrm{X}_{\mathrm{L}}$ and $\mathrm{X}_{\mathrm{U}}$, respectively, and their function values $\mathrm{F}_{\mathrm{L}}$ and $\mathrm{F}_{\mathrm{U}}$ are known. During the process, the initial interval of uncertainty $\left(\mathrm{X}_{\mathrm{U}}-\mathrm{X}_{\mathrm{L}}\right)$ reduces to a fraction $(\varepsilon)$ of the initial interval. If $X_{1}$ and $X_{2}$ are two intermediate points with the function values of $F_{1}$ and $\mathrm{F}_{2}$, respectively, such that $\mathrm{X}_{1}<\mathrm{X}_{2}$, then the interval of uncertainty is reduced in each iteration by the equation,

$$
X_{1}=(1-\tau) X_{L}+\tau X_{U}
$$


Or

$$
X_{2}=\tau X_{L}+(1-\tau) X_{U}
$$

where $\tau=0.38197$ is a predefined factor in GSM. During the iterative process, if $F_{1}>F_{2}, X_{L}$ is replaced by $X_{1}$ and $X_{1}$ is replaced by $X_{2}$, then $X_{2}$ is calculated by equation(2). if $F_{1}<F_{2}, X_{U}$ is replaced by $X_{2}$ and $X_{2}$ is replaced by $X_{1}$, then $X_{1}$ is updated by equation (1).

If there are constrains, then the design may be initially feasible or infeasible. Either way, an arbitrary initial step is estimated by using the slope of the function, next the bounds on the solution should be found and then reduced using GSM. Finally, the last four function values $\left(\mathrm{X}_{\mathrm{L}}, \mathrm{X}_{1}, \mathrm{X}_{2}, \mathrm{X}_{\mathrm{U}}\right)$ can be interpolated with a cubic polynomial approximation or they may be compared and the best approximate value can be picked.

Fig. $2 \mathrm{~b}$ shows a typical crack propagation path which has originated from an initial or parent crack in several increments, where $\bar{a}_{i}$ is the size of the crack extension in each step. In each increment, the crack kink angle can be calculated iteratively using the GSM. During the iterative process, the new kinked crack geometry is continuously changing and it requires automatic re-meshing. Each iteration includes three main stages: Firstly, analysis of the stress, displacement and elastic compliance is carried out. Secondly, using the boundary element shape sensitivities, the derivative of the elastic compliance with respect to the crack extension at the tip of the possible new crack, which is equivalent to $J_{1}$-integral, is determined. Finally, the local stability and incremental path for mixed mode cracks is examined, where incremental changes in crack length require release of sticking boundary elements along the crack path, updating of crack geometry and automatic re-meshing of the elements between the sub-regions. The reason is that the crack direction in each iteration changes.

Clearly crack instability is associated with the stationary value of the total energy. Beyond this point, the energy released during an incremental crack extension exceeds the energy required to create new crack surfaces. Therefore, at the onset of the crack growth,

$$
J_{1}=\frac{d E}{d a}=G_{c r i t}
$$

where $\mathrm{G}_{\text {crit }}$ is the critical SERR. During the iterative process, it is assumed that the applied external forces are large enough so that the fracture criterion, equation (3), holds and the size of the crack extension $\bar{a}_{i}$ during each increment is kept constant. It should be noted that the algorithm is capable of changing these factors during the optimization process. 
Fig. 3 shows the flow diagram of the algorithm used to simulate crack growth. This includes four main stages:

-An analysis of the stresses and displacements for a given cracked structure using the BEM.

- Sensitivity analysis corresponding to possible changes to the crack geometry using the BEM.

-Numerical optimization to predict the crack growth direction using the GSM.

- Automatic regeneration of the boundary element mesh.

The following reviews the stress analysis and sensitivity analysis for a cracked structure using the BEM and also application of the proposed algorithm to investigate the effect of material anisotropy on the crack propagation of composites.

\section{Review of the boundary element method for anisotropic elasticity}

The BEM is based on the unit load solutions in an infinite body, known as the fundamental solutions, used with the reciprocal work theorem and appropriate limit operations. The Boundary Integral Equation (BIE) of the anisotropic materials is an integral constraint equation relating boundary tractions $\left(\mathrm{t}_{\mathrm{j}}\right)$ and boundary displacements $\left(\mathrm{u}_{\mathrm{j}}\right)$ and it may be written as [23]

$C_{j k} u_{j}(P)+\int_{s} T_{j k}(P, Q) u_{j}(Q) d s(Q)=\int_{s} U_{j k}(P, Q) t_{j}(Q) d s(Q) \quad j, k=1,2$

$\mathrm{P}\left(\zeta_{1}, \zeta_{2}\right)$ and $\mathrm{Q}\left(\mathrm{x}_{1}, \mathrm{x}_{2}\right)$ are the field and load points, respectively. $\mathrm{U}_{\mathrm{jk}}(\mathrm{P}, \mathrm{Q})$ and $\mathrm{T}_{\mathrm{jk}}(\mathrm{P}, \mathrm{Q})$ are the fundamental solutions that represent the displacements and tractions, respectively, in the $x_{k}$ direction at $\mathrm{Q}$ because of a unit load in the $\mathrm{x}_{\mathrm{j}}$ direction at $\mathrm{P}$ in an infinite body. The constant term $\mathrm{C}_{\mathrm{jk}}$ depends on the local geometry of the boundary at $\mathrm{P}$ and is equal to $\frac{1}{2} \delta_{j k}$ for a smooth boundary, where $\delta_{\mathrm{jk}}$ is the Kronecker delta. The load point $\mathrm{P}$ and the field point $\mathrm{Q}$ are defined on the complex plane as

$z_{k}=\left(x_{1}-\zeta_{1}\right)+\mu_{k}\left(x_{2}-\zeta_{2}\right) \quad k=1,2$

$\mu_{1}, \mu_{2}$ are the roots of the characteristic equation of the anisotropic material [24],

$a_{22}-2 \mu a_{26}+\left(2 a_{12}+a_{66}\right) \mu^{2}-2 a_{16} \mu^{3}+a_{11} \mu^{4}=0$.

The coefficients $a_{\mathrm{jk}}$ are the elastic compliance of the material. For especially orthotropic materials, $a_{16}=a_{26}=a_{63}=0$. [25].

The fundamental solutions for displacements and tractions, respectively, can be written as 


$$
\begin{aligned}
& U_{j k}=2 \operatorname{Re}\left[r_{k 1} A_{j 1} \ln \left(z_{1}\right)+r_{k 2} A_{j 2} \ln \left(z_{2}\right)\right\rfloor \\
& T_{j 1}=2 n_{1} \operatorname{Re}\left[\mu_{1}^{2} A_{j 1} / z_{1}+\mu_{2}^{2} A_{j 2} / z_{2}\right]-2 n_{2} \operatorname{Re}\left[\mu_{1} A_{j 1} / z_{1}+\mu_{2} A_{j 2} / z_{2}\right] \\
& T_{j 2}=-2 n_{1} \operatorname{Re}\left[\mu_{1} A_{j 1} / z_{1}+\mu_{2} A_{j 2} / z_{2}\right]+2 n_{2} \operatorname{Re}\left[A_{j 1} / z_{1}+A_{j 2} / z_{2}\right]
\end{aligned}
$$

where $\mathrm{n}_{\mathrm{j}}$ are the unit outward normal components at $\mathrm{Q}$ with respect to the $\mathrm{x}_{1}-\mathrm{x}_{2}$ coordinate system. The constants $r_{\mathrm{kj}}$ are

$$
\begin{aligned}
& r_{1 j}=a_{11} \mu_{j}^{2}+a_{12}-a_{16} \mu_{j} \\
& r_{2 j}=a_{12} \mu_{j}+a_{22} / \mu_{j}-a_{26}
\end{aligned}
$$

and $\mathrm{A}_{\mathrm{jk}}$ are complex constants that can be obtained from the following set of equations:

$$
\begin{aligned}
& A_{j 1}-\bar{A}_{j 1}+A_{j 2}-\bar{A}_{j 2}=\delta_{j 2} / 2 \pi i \\
& \mu_{1} A_{j 1}-\bar{\mu}_{1} \bar{A}_{j 1}+\mu_{2} A_{j 2}-\bar{\mu}_{2} \bar{A}_{j 2}=-\delta_{j 1} / 2 \pi i \\
& r_{11} A_{j 1}-\bar{r}_{11} \bar{A}_{j 1}+r_{21} A_{j 2}-\bar{r}_{21} \bar{A}_{j 2}=0 . \\
& r_{12} A_{j 1}-\bar{r}_{12} \bar{A}_{j 1}+r_{22} A_{j 2}-\bar{r}_{22} \bar{A}_{j 2}=0 .
\end{aligned}
$$

An elastic body with several cracks may be divided into several sub-regions where the crack faces coincide with the boundaries of the sub-regions. The multi-region modeling approach was first exploited for crack modeling by Blandford et al [26] where BIE (Equation 4) is employed individually for each sub-region(L) in turn.

$$
C_{j k}^{(L)} u_{j}^{(L)}(P)+\int_{s(L)} T_{j k}^{(L)}(P, Q) u_{j}^{(L)}(Q) d s^{(L)}(Q)=\int_{s} U_{j k}^{(L)}(P, Q) t_{j}^{(L)}(Q) d s^{(L)}(Q) \quad j, k=1,2
$$

The boundary-element implementation of equation (10) entails boundary discretization. Quadratic isoparametric elements can be employed for the analyses. Substitution of these isoparametric representations into equation (10) will result in a set of linear algebraic equations for the unknown displacements and tractions at the nodes on the boundary of the solution domain [27-29].

Then, appropriate continuity and equilibrium conditions are applied at the common subregion interface before the linear algebraic equations are solved. For example, for two subregions, $R_{a}$ and $R_{b}$, respectively,

$$
u_{i}^{R a}=u_{i}^{R b} \quad, \quad t_{i}^{R a}+t_{i}^{R b}=0 .
$$

\section{Sensitivities of the structural response for a multi-region domain and strain energy release rate}

In Ref.[3] the crack length of arbitrary geometric shape was selected as the shape design variable. Then, the shape variable was associated with the coordinates of a series of boundary 
nodes located on the crack surface. Thus, the relevant velocity terms were applied together in the sensitivity analysis with respect to that variable to determine the gradients of the elastic compliance or the SERR with respect to the crack length extension.

The following shows how the sensitivities of displacements, stresses and elastic compliance with respect to the boundary point coordinates for a multi-region domain were calculated.

Direct differentiation of the BIE for each sub-region with respect to a design variable, $\mathrm{x}_{\mathrm{h}}(\mathrm{h}=1,2)$ (which is most likely to be the coordinate of a node on the crack surface) results in the following equation [3]:

$$
\begin{aligned}
& C_{j k}^{(L)} \frac{\partial u_{j}^{(L)}(P)}{\partial x_{h}}+\frac{\partial C_{j k}^{(L)}}{\partial x_{h}} u_{j}^{(L)}(P)+\int_{s(L)}\left[\frac{\partial T_{j k}^{(L)}(P, Q)}{\partial x_{h}} u_{j}^{(L)}(Q)+T_{j k}^{(L)}(P, Q) \frac{\partial u_{j}^{(L)}(Q)}{\partial x_{h}}\right] d s^{(L)}(Q)+ \\
& \int_{s(L)}\left[T_{j k}^{(L)}(P, Q) u_{j}^{(L)}(Q)\right] \frac{\partial\left[d s^{(L)}(Q)\right]}{\partial x_{h}}=\int_{s(L)}\left[\frac{\partial U_{j k}^{(L)}(P, Q)}{\partial x_{h}} t_{j}^{(L)}(Q)+U_{j k}^{(L)}(P, Q) \frac{\partial t_{j}^{(L)}(Q)}{\partial x_{h}}\right] d s^{(L)}(Q) \\
& \int_{s} U_{j k}^{(L)}(P, Q) t_{j}^{(L)}(Q) \frac{\partial\left[d s^{(L)}(Q)\right]}{\partial x_{h}} \quad j, k=1,2
\end{aligned}
$$

The derivatives of the terms that only depend on the geometry will be carried out similar to the isotropic materials [28]. The derivatives of the kernels for anisotropic materials will be as follows [29]:

$$
\begin{aligned}
\frac{\partial U_{j k}}{\partial x_{h}} & =2 \frac{\partial}{\partial x_{h}}\left[\operatorname{Re}\left(r_{k 1} A_{j 1} \ln \left(z_{1}\right)+r_{k 2} A_{j 2} \ln \left(z_{2}\right)\right)\right] \\
\frac{\partial T_{j 1}}{\partial x_{h}} & =2 n_{1} \frac{\partial}{\partial x_{h}}\left[\operatorname{Re}\left(\frac{\mu_{1}^{2} A_{j 1}}{z_{1}}+\frac{\mu_{2}^{2} A_{j 2}}{z_{2}}\right)\right]+2 \operatorname{Re}\left(\frac{\mu_{1}^{2} A_{j 1}}{z_{1}}+\frac{\mu_{2}^{2} A_{j 2}}{z_{2}}\right) \frac{\partial\left(n_{1}\right)}{\partial x_{h}} \\
& -2 n_{2} \frac{\partial}{\partial x_{h}}\left[\operatorname{Re}\left(\frac{\mu_{1} A_{j 1}}{z_{1}}+\frac{\mu_{2} A_{j 2}}{z_{2}}\right)\right]-2 \operatorname{Re}\left(\frac{\mu_{1} A_{j 1}}{z_{1}}+\frac{\mu_{2} A_{j 2}}{z_{2}}\right) \frac{\partial\left(n_{2}\right)}{\partial x_{h}} \\
\frac{\partial T_{j 2}}{\partial x_{h}} & =-2 n_{1} \frac{\partial}{\partial x_{h}}\left[\operatorname{Re}\left(\frac{\mu_{1} A_{j 1}}{z_{1}}+\frac{\mu_{2} A_{j 2}}{z_{2}}\right)\right]-2 \operatorname{Re}\left(\frac{\mu_{1} A_{j 1}}{z_{1}}+\frac{\mu_{2} A_{j 2}}{z_{2}}\right) \frac{\partial\left(n_{1}\right)}{\partial x_{h}} \\
& +2 n_{2} \frac{\partial}{\partial x_{h}}\left[\operatorname{Re}\left(\frac{A_{j 1}}{z_{1}}+\frac{A_{j 2}}{z_{2}}\right)\right]+2 \operatorname{Re}\left(\frac{A_{j 1}}{z_{1}}+\frac{A_{j 2}}{z_{2}}\right) \frac{\partial\left(n_{2}\right)}{\partial x_{h}}
\end{aligned}
$$

The coefficients $\mu_{\mathrm{j}}$ and $\mathrm{A}_{\mathrm{jk}}$ depend on the material properties and are independent of the boundary nodes coordinates. 
For calculation of the sensitivities of an elastic body which is divided into several subregions, the boundary constraints, equation 17 , must be differentiated with respect to the design variable. The differentiated form of the boundary constraints will create relationships between the derivatives of the displacements and tractions of the node pairs. For the stick node pair $\left(\mathrm{N}^{*}{ }_{\mathrm{a}}, \mathrm{N}^{*}{ }_{\mathrm{b}}\right)$ the differentiated form of equation (11) is,

$$
\frac{d u_{i}^{N a}}{d x_{h}}=\frac{d u_{i}^{N b}}{d x_{h}} \quad, \quad \frac{d t_{i}^{N a}}{d x_{h}}+\frac{d t_{i}^{N b}}{d x_{h}}=0 . \quad i=1,2
$$

Thus, the design sensitivity analysis is carried out by direct differentiation of the structural response with respect to design variables. Following the calculation of displacement gradients, the derivatives of stresses can be obtained.

The elastic compliance is evaluated as the strain energy of the structure

$$
E_{s}=\frac{1}{2} \int_{s} t_{j} u_{j} d s
$$

The derivatives of the elastic compliance, with respect to the boundary point coordinate, $\mathrm{x}_{\mathrm{h}}$, can also be calculated analytically as follows:

$$
\frac{\partial E_{s}}{\partial x_{h}}=\frac{1}{2}\left[\int_{s} \frac{\partial t_{j}}{\partial x_{h}} u_{j} d s+\int_{s} t_{j} \frac{\partial u_{j}}{\partial x_{h}} d s+\int_{s} u_{j} t_{j} \frac{\partial}{\partial x_{h}}(d s)\right]
$$

Ref.[30] presents the novel application of the boundary element method (BEM) to the optimum shape design of composite structures. The sensitivities of the elastic compliance coupled with the feasible direction method, as the optimization algorithm, and an automatic mesh generator were employed for the shape optimization of anisotropic structures for the highest stiffness. The constraints were upon stresses, weight and geometry of the structure. The effect of engineering constants on the optimum shape of composite structures was studied. There are hardly any other publications available on the shape optimisation of composite structures.

For a cracked structure, when the boundary points on the crack surfaces are treated as the design variables, the rate of energy released per unit of crack extension along the $x^{*}{ }_{1}$ axis is the same as the derivative of the elastic compliance of the structure or $\mathrm{J}_{1}$ integral.

The J-integral method was first developed by Rice [2] to characterize fracture for two dimensional configurations modeled by a linear or nonlinear elastic material. For such a material of unit thickness containing a traction free crack, the $\mathrm{J}_{\mathrm{k}}$ integral is defined as

$$
J_{k}=\oint_{c}\left(W n_{k}-t_{i} u_{j, k}\right) d s
$$


where $\mathrm{j}, \mathrm{k}=1,2, \mathrm{~W}$ is the strain energy density, $\mathrm{S}$ is a generic contour surrounding the crack tip, $t_{i=} \sigma_{i j} n_{i}$ are the traction components defined along the contour and $n_{i}$ are the components of the unit outward normal to the contour path. Using the J-integral method, a circular path may be generated with the centre at the crack tip, defining the number of internal points to be computed, beginning on one crack face and finishing on the other. With the numerical integration of equation (17), $\mathrm{J}_{1}$ can then be determined.

In contrast to the J-integral method which would require the computation of stresses and strains at a series of internal points around the crack for evaluation of the path-independent integrals, here the SERR or $J_{1}$ integral is evaluated by direct differentiation of the structural response for a multi-region domain.

It should be mentioned that for the prediction of a crack propagation path, the SERRs at the existing crack tip and new cracks must be evaluated. Therefore, compared to the J-integral method, not only is the accuracy of the present method very high, but in terms of computational modeling and analysis, it is much more efficient.

\section{Results and discussuion}

The method presented here has been applied to two mixed mode crack problems with different material properties. The engineering constants of the selected materials for the analysis are shown in Table 1 . Materials 1 and 2 are isotropic where $\mu_{1}=\mu_{2}=\mathrm{i}$. Material 3 is Graphite-epoxy with $E_{1} / E_{2}=12.37, G_{12} / E_{2}=0.82$ and $v_{12}=0.21$. For Material 4 the shear modulus and Poisson's ratio were fixed and Young's moduli were calculated as a function of the parameter $\phi=E_{1} / E_{2}$. The roots of the characteristic equation of materials 3 and 4 are purely imaginary. Material 5[31] has complex roots where $\mathrm{E}_{1}=\mathrm{E}_{2}, \mathrm{G}_{12} / \mathrm{E}_{2}=2.94$ and $v_{12}=0.845$. In order to examine the effect of the shear modulus on the crack kink angle the fictious material $5 \mathrm{~b}$ was used. This material has similar engineering constants to material 5 , except its shear modulus is $\mathrm{G}_{12} / \mathrm{E}_{2}=1.05$.

The above materials were selected because the roots of their characteristic equations fall into one or other of the following categories: a) pure imaginary and equal, b) pure imaginary and unequal or c) complex.

It should be noted that every component is being treated as a lamina that has four engineering constants, $E_{1}, E_{2}, G_{12}$ and $v_{12}$ with a lamina orientation angle of zero. When the fibre orientation is greater than zero the equivalent engineering constants are determined and 
subsequently used in the analysis. Here, an isotropic material is assumed as if it is anisotropic $\left[E_{1}=E_{2}, G_{12}=0.5 E_{1}\left(1+v_{12}\right)\right]$. In each case the meshes were refined to assure the convergence of the solution. The results include the crack kink angle and/or the crack propagation path of a rectangular plate having a central slant crack or a curve crack subject to tension. Different material properties, crack inclination angles or arc angles are studied. The main objective has been to investigate the accuracy of the present method and also to investigate the effect of material anisotropy on the crack kink angle and propagation path using the boundary element shape sensitivities coupled with an optimization algorithm.

Figs. 4-5 show a rectangular plate with a central slant crack or a circular arc crack subject to the uniform tensile stress $(\sigma)$ applied to the ends of each plate, respectively. The SIFs or SERRs of these examples for different anisotropic material properties obtained using the boundary element shape sensitivities were presented in Ref.[3]. Here, each model was divided into two sub-regions and the BE mesh of each region consisted of 60-70 elements.

Early contribution to the solution of the centre slant cracked plate under biaxial loading belongs to Erdogan and Sih [8] who obtained the crack kink angle based on the MTS criterion. Their predictions were compared with their experimental results on the peliglass sheets. Williams and Ewing [32] performed additional work and their experimental results showed that the inclusion of the non-singular term in the series expansion for the stress distribution around the crack tip can produce an improved correlation with the predicted values of the crack kink angle and the critical SIF. In particular, for the region $50^{\circ}<\varphi<90^{\circ}$, where various theories differ. In their analytical approach, Williams and Ewing modified the MTS theory of Erdogan and Sih [8], taking account of terms in the series expansion as well as the singular term, as discussed by Cotterell [33]. Williams and Ewing[32] reported that at $\varphi=90^{\circ}$ the crack kink angle tends to be $-90.0^{\circ}$ and not $-70.5^{\circ}$ as predicted by Erdogan and Sih [8].

Later, Sih proposed the S-criterion. Based on this criterion, a crack grows in the direction of minimum strain energy density or when the SIF reaches a critical value. The strain energy density in the vicinity of the crack tip (Fig. 1) for an isotropic material is given by [9]

$$
\frac{d E}{d V}=\frac{1}{\pi r}\left(b_{11} K_{I}^{2}+2 b_{12} K_{I} K_{I I}+b_{22} K_{I I}^{2}+b_{33} K_{I I I}^{2}\right)+(\text { non }- \text { singular terms })
$$

where $b_{i j}(i, j=1,2)$ depends on the material properties and the polar angle $\theta[9]$. Therefore, the strain energy density function has a (1/r) singularity at the crack tip. Hence, he proposed that the expression 


$$
S=\left(b_{11} K_{I}^{2}+2 b_{12} K_{I} K_{I I}+b_{22} K_{I I}^{2}+b_{33} K_{I I I}^{2}\right) / \pi
$$

represents the intensity of the strain energy density field in the vicinity of the crack tip. Based on this theory, the stationary values of $\theta_{0}$ are related to the crack angle $\beta$ by the following equation [9],

$$
2(1-2 v) \sin \left(\theta_{0}-2 \beta\right)-2 \sin \left[2\left(\theta_{0}-\beta\right)\right]-\sin ^{2} \theta_{0}=0 .
$$

where $\beta$ is the direction of the crack surface with respect to the $y$-axis, $\beta=90-\varphi$. It should be noted noted that $\mathrm{K}_{\mathrm{III}}$ is equal to zero for mixed mode I-II loading.

Here, the crack kink angle of a central slant crack of length $\mathrm{a} / \mathrm{w}=0.4$ in a rectangular steel plate of height to width ratio of $\mathrm{h} / \mathrm{w}=2$ subjected to tension $(\sigma)$ is determined. The crack is inclined with the angle of $\varphi=45^{\circ}$ with respect to the $\mathrm{x}$ axis. This plate was also analysed in ABAQUS benchmarks manual [34]. In Abaqus/Standard they provide three criteria for only homogeneous, isotropic linear elastic materials: the MTS criterion, the Max. SERR criterion, and the $\mathrm{K}_{\mathrm{II}}=0$ criterion [35], which implies that at the crack tip $\mathrm{K}_{\mathrm{II}}$ is zero as the crack extends.

ABAQUS results using the J-integral method and based on the above three criteria are shown in Table 2. This table also shows the present results when the objective function is the Max. SERR or MTS, respectively, where good agreement can be observed.

This case study is used to verify the accuracy of the optimization algorithm. Since the crack kink angle is the only variable, a series of analyses have been performed by just changing the crack kink angle or polar angle $\left(\theta_{0}\right)$, between 0 and -90 degrees, with $\bar{a}=0.007 w$, and keeping the other geometrical constraints fixed. For each geometry, the derivative of the elastic compliance with respect to the crack extension at the tip of the new crack has been computed. Fig. 6 shows the variation of the SERR with respect to the crack kink angle $\left(-\theta_{0}\right)$ when $\varphi=45^{\circ}$. It can be observed that the objective function SERR is unimodal and has a stationary condition when $\theta_{0}$ is between -50 and -60 degrees. The corresponding result obtained using the GSM is $-54.31^{\circ}$ which is shown in the square brackets in the legend section of Fig. 6.

Fig. 6 also shows similar results for the crack inclination angles of $\varphi=15^{\circ}$ and $\varphi=30^{\circ}$, respectively. The crack kink angles obtained, using the optimization algorithm, are $\left(-22.88^{\circ}\right)$ and $\left(-38.74^{\circ}\right)$, respectively, which agree very well with the corresponding stationary points for $\theta_{0}$ shown on the graph. It can also be observed that for the three crack inclination angles, the 
angle of each new crack with respect to the $x$-axis is varying between $\left(-8^{\circ}\right)$ and $\left(-9^{\circ}\right)$. Therefore, the crack surface almost branches normal to the applied load direction.

Fig. 7 shows the variation of the crack kink angle $\left(\theta_{0}\right)$ vs crack inclination angle $(\varphi)$ of the above isotropic plate, where $\varphi$ varies between 5 and 70 degrees. The results are computed based on the Max. SERR and MTS criteria. For the MTS criterion, the same optimization algorithm has been employed except the maximum tangential stress near the crack tip is considered as the objective function. It can be observed that for $\varphi \leq 45^{\circ}$ both criteria almost predict identical values for the initial crack kinking angle while for $\varphi \succ 45^{\circ}$ the predictions are slightly different.

Fig. 7 also shows the results obtained for an infinite plate with a central slant crack based on the S-criterion using equation (20)[9], which relatively shows a good agreement.

Next, the present method is used to simulate crack propagation path in a rectangular titanium plate (Material No. 2) with a central slant crack subject to tension and comparing the results with the corresponding experimental results reported in Ref.[36]. In Ref.[36] two centre crack specimens were tested, designated CGS-04 and CGS-05, having crack angles of $\varphi=47^{\circ}$ and $60^{\circ}$, respectively. Each specimen was cycled to final fracture at a constant load range, and the position ( $\mathrm{x}$ and $\mathrm{y}$ ) of the crack tip was measured between load intervals at both sides of the initial slot. The crack paths, represented at a series of straight line increments for the period of crack growth in which the crack surface remained normal to the thickness of the specimen were sketched. Using their published crack growth data, their experimental crack propagation path for the right side of the crack specimen CGS-04 $\left(\varphi=47^{\circ}\right)$ is plotted on Fig. 8 , where $\mathrm{a} / \mathrm{w}=0.176$ and $\mathrm{h} / \mathrm{w}=4$. Fig. 8 also shows the results of the current study after 20 increments, where excellent agreement can be observed. The present crack growth data including the angle of each crack surface with respect to the $\mathrm{x}$-axis and the previous crack surface, respectively, with the incremental crack extension of $\bar{a}=0.007 \mathrm{w}$ are shown in Table 3. As shown, the initial crack kink angle predicted by the current study is $-56.12^{\circ}$, while $54.0^{\circ}$ was the experimental result reported in Ref.[36].

Next, the effect of material anisotropy on the crack kink angle and growth path of a plate with the central slant crack was examined. For the sake of comparison, the steel plate which was studied earlier $[\mathrm{a} / \mathrm{w}=0.4$ and $\mathrm{h} / \mathrm{w}=2]$ but with graphite-epoxy material property (material No. 3) was analysed. Here, the results of two different fibre orientation angles are presented, $\psi=0^{\circ}$ and $90^{\circ}$, respectively. For each fibre angle, the crack inclination angles of $15^{\circ}, 30^{\circ}$ and 
$45^{\circ}$ were tested. A series of analyses were performed by just changing the crack kink angle between 0 and -90 degrees. For each geometry, the derivative of the elastic compliance with respect to the crack extension at the tip of the new crack or SERR was computed. Fig. 9 shows the variation of the SERR with respect to the crack kink angle $\left(\theta_{0}\right)$ for the crack inclination angles of $15^{\circ}, 30^{\circ}$ and $45^{\circ}$, respectively. Therefore, either the fibres were placed along the load direction $\left(\psi=90^{\circ}\right)$ or perpendicular to it $\left(\psi=0^{\circ}\right)$. It can be observed that for each crack inclination angle the stationary value of $\theta_{0}$ when $\left(\psi=0^{\circ}\right)$ is higher than the corresponding value when $\left(\psi=90^{\circ}\right)$. Using the optimization algorithm, the crack kink angles for each case was also determined. For the crack inclination angles of $45^{\circ}, 30^{\circ}, 15^{\circ}$, when $\psi=90^{\circ}$, the kink angles were $-50.60^{\circ},-33.65^{\circ},-15.99^{\circ}$, while for $\psi=0^{\circ}$, the kink angles were $-58.88^{\circ},-39.88^{\circ}$ and $-26.24^{\circ}$, respectively. Similar results were obtained for the intermediate values of $\psi$ between 0 and 90 , but for the sake of brevity these are not presented here. However, for each fibre angle, the trend of variation of SERR vs $\left(\theta_{0}\right)$ was similar to the curves shown in Fig. 9.

Fig. 10 shows the variation of the crack kink angle $\left(\theta_{0}\right)$ vs crack inclination angle $(\varphi)$ of the graphite-epoxy plate, for $\psi=0$. and $90^{\circ}$, respectively. For the sake of comparison, the results of the steel plate, based on the Max. SERR criterion, which were presented in Fig. 7, are also included in Fig. 10. It can be observed that the trends of variation of $\left(\theta_{0}\right)$ vs $(\varphi)$ for steel and the graphite-epoxy (when $\psi=90$.) plates are similar, but the predicted kink angles for the steel plate are positioned between the corresponding values for the graphite-epoxy plate when $\psi=0$. and 90, respectively. When $\psi=0$. and $20^{\circ} \prec \varphi \prec 40^{\circ}$, the predicted kink angles of the steel and graphite-epoxy are almost the same, although their overall trends of variations are different.

Next, the effect of fibre orientation angle $(\psi)$ on the crack kink angle $\left(\theta_{0}\right)$ of the above graphite-epoxy plate for the crack inclination angle of $\varphi=45^{\circ}$ was examined. Fig. 11 shows the change of $\left(-\theta_{0}\right)$ with respect to the fibre angle $(\psi)$. It can be seen that the overall change of $\left(\theta_{0}\right)$ is about 8 degrees, from $-58.88^{\circ}$ to $-50.60^{\circ}$, when $\psi$ is changing from 0 to 90 degrees. It can be observed that for $0^{\circ}<\psi<20^{\circ}$ there is a small drop of $\left(\theta_{0}\right)$ and for $20^{\circ}<\psi<50^{\circ},\left(\theta_{0}\right)$ is almost independent of the fibre angle. Finally, $\left(\theta_{0}\right)$ has a sharp drop when $\psi>50^{\circ}$. This may be because when the fibre angle is less that the crack angle, the variation $\left(\theta_{0}\right)$ vs $\psi$ is almost negligible. This would require further investigation. 
Next, the above plate with material No. 4 is tested, where $E_{1}=G_{12}\left(\phi+2 v_{12}+1\right)$, the shear modulus, $\mathrm{G}_{12}$, and the Poisson's ratio, $v_{12}$, have fixed values of $6 \mathrm{GPa}$ and 0.03 , respectively. The parameter $\phi=\mathrm{E}_{1} / \mathrm{E}_{2}$ varies from 0.1 to 4.5 . Fig. 12 shows the crack kink angle $\left(\theta_{0}\right)$ vs crack inclination angle $(\varphi)$ of the plate, for $\phi=0.1$ and 4.5 , respectively. The results of the steel plate which were presented in Fig. 7, are also included in Fig. 12. It can be observed that for $\phi=0.1$, when $E_{2}>>E_{1}$, the trend of variation is almost the same as the graphite-epoxy having fibres along the load direction (Fig.10). In Fig. 12 the curve of $\phi=4.5$ is located beneath the steel curve, indicating that when $E_{1}>E_{2}$ the kink angles are slightly higher than the corresponding values of the steel plate.

Fig. 13 shows the variation of the crack kink angle $\left(\theta_{0}\right)$ vs the parameter $(\phi)$ for the crack inclination angles of $15^{\circ}, 30^{\circ}$ and $45^{\circ}$, respectively. For $\phi>1.0$, the kink angle is almost independent of $\phi$ and for $\phi<1.0$, the effect of $\phi$ on the crack kink angle is apparent. It can be concluded that for materials 3 and 4 , the crack kink angle $\left(\theta_{0}\right)$ was mainly influenced by the ratio of the equivalent Young's modulus perpendicular and along the load direction $\left(E_{x} / E_{y}\right)$, respectively. When $\mathrm{E}_{\mathrm{x}} / \mathrm{E}_{\mathrm{y}}=1.0$, the anisotropic material behaved almost the same as the isotropic plate.

The results for material No. 5 when $\mathrm{E}_{1} / \mathrm{E}_{2}=1.0$ but having high values of the shear modulus and the Poisson's ratio, 55.6GPa and 0.845 , respectively, are also included in Fig. 12. It can be observed that for this material although $\mathrm{E}_{\mathrm{x}} / \mathrm{E}_{\mathrm{y}}$ is equal to 1.0, the high values of the shear modulus and Poisson's ratio have influenced the variation of $\left(\theta_{0}\right)$ vs $(\varphi)$.

Next, the crack propagation paths of the steel and graphite-epoxy plates are compared. The analysis was performed for a crack inclination angle of $45^{\circ}$ with the crack extension increment $\bar{a}=0.007 \mathrm{w}$. The analysis was performed in 25 increments. Fig. 14 shows the propagation path for the right side of the crack of each plate. It can be seen that the crack growth of the steel plate is almost identical to the Titanium plate which was studied earlier (Fig. 8). The crack growth path of the graphite epoxy plate when $\psi=0$. was nearly parallel to the fibre direction and almost normal to the direction of the applied load. However, for the graphite-epoxy plate when $\psi=90^{\circ}$, after a few increments the crack growth path was gradually deflected towards the fibre direction. The deformed shape of the plate, scaled up by a factor of 9, is also shown in Fig. 14. Although, for the graphite-epoxy plate when $\psi=0$, initially the branching angle was slightly higher than the corresponding value when $\psi=90$, the crack grew parallel to the stiffer material direction. It was observed that for $\psi=90$, the parent crack was 
gradually turning towards the fibres which were parallel to the direction of the applied load. Similar results for the crack inclination angle of $\varphi=30$ are shown in Fig. 15, where similar trends of variations can be seen.

In order to apply the current method for the curved crack geometries, the problem of a circular arc crack with the semi-angle of $\beta$ in a rectangular plate $(\mathrm{h} / \mathrm{w}=2, \mathrm{r} / \mathrm{w}=0.4)$ subject to tension is analysed, as shown in Fig. 5. First, it is assumed that the material of the plate is isotropic, such as steel (material No.1). Fig.16 shows the variation of the crack kink angle $\left(\theta_{0}\right)$ vs crack semi-angle $(\beta)$ based on the MSERR and MTAS criteria. The results show that for small crack semi-angles $\left(\beta<15^{\circ}\right)$ both theories give almost identical results. However, when $\left(\beta>15^{\circ}\right)$, the MTS theory predicts slightly higher branching angles with respect to the Max. SERR theory. It can also be seen that the crack kink angle has almost a linear variation with respect to the crack semi-angle when calculated based on the Max. SERR theory.

Fig. 17 shows similar results obtained for the same plate with material numbers 3, 4, 5, and 5b respectively, based on the Max. SERR criterion. The results for the steel plate have also been included in Fig. 17. For the graphite-epoxy material, the fibre angles of $\psi=0^{\circ}$ and $\psi=90^{\circ}$ are considered while for material No. 4 the parameter $\phi$ is selected to be 0.1 and 4.5 , respectively. The elastic constants of materials 5 and $5 \mathrm{~b}$ are identical, except the shear moduli which are 55.6GPa and 20GPa, respectively. Fig. 17 shows that the effect of material anisotropy on the crack kink angles of curve cracks is less apparent. However, by comparing the results of materials 5 and $5 \mathrm{~b}$, it can be observed that in this case the shear modulus has a great effect on the crack kink angle.

Fig. 18 shows the propagation paths for the right side of the crack of the steel plate and plate with the material No. 5 , for the crack semi-angle of $60^{\circ}$ with the crack extension increment of $\bar{a}=0.007 \mathrm{w}$ which was kept constant. The analysis was performed in 25 increments. For the first few increments, both cracks had similar growth while they gradually branched at different directions. For both materials $E_{1}=E_{2}$, therefore, the difference between the crack propagation paths is due to the different values of shear moduli and Poisson's ratios. For steel, $\frac{G_{12}}{E_{2}}=0.38, v_{12}=0.3$ whereas for material No. 5, $\frac{G_{12}}{E_{2}}=2.94, v_{12}=0.84$. The deformed shape of the plate, scaled up by a factor of 9, is also shown on Fig. 18.

It should be noted that Ref. [37] is a recent article in which the prediction of the crack kinking angle in brittle, isotropic and homogeneous materials is discussed. 
Early application of the BEM involving interactions of multiple cracks and rigid lines representing fibres dates back to 1990s [38-41]. The modelling of crack and fibre interactions is essential for a comprehensive model of damage in composites. However, the present study focuses on the crack growth of a lamina at the macro scale where the equivalent engineering constants are used for the analysis. At present, the most common method used in industry for the crack analysis is the J-Integral in-conjunction with the FEM. The application of the Jintegral with the BEM will reduce the time of modelling and analysis but would still require the calculation of stresses and strains at a series of internal points around the crack for evaluation of the path-independent integrals. Using the boundary element shape sensitivities with the design variables which represent the crack surfaces, the computational efficiency will be greatly improved.

It should be mentioned that the Virtual Crack Closure Technique (VCCT) is widely used for computing SERR. It was originally proposed by Rybicki and Kannien [42] for 2D crack problems and was then extended to 3D by Shivakumar et al [43]. In Refs.[5-6] the VCCT with FEM was used by the author to calculate SERR for delaminated composite cylindrical shells in which the direction of crack growth was already available.

The novelty of the present work lies in the coupling of an optimization technique with crack shape sensitivity analysis for the prediction of crack growth, using the BEM.

\section{Conclusion}

Following a brief review of the mathematical basis of the BIE method for multi-region domains, analytical differentiation of the BIE with respect to the positions of the boundary nodes was discussed. It was shown how the length of a crack of arbitrary shape can be treated as the shape design variable and using the boundary element shape sensitivities the $\mathrm{J}_{1}$-integral or SERR for two-dimensional anisotropic elastic solids can be determined. The prediction of the crack kink angle and propagation path using the boundary element shape sensitivities coupled with an optimization algorithm and an automatic mesh generator was explained in detail. The accuracy and efficiency of the method in calculating the Max. SERR at the tip of the existing crack and the new cracks during the period of crack growth was demonstrated. The results show that although the SIF is of fundamental importance in the prediction of brittle failure using linear elastic fracture mechanics, for composite laminates, the direct evaluation of the SERR would easily characterise their crack instability and propagation path. In contrast to the J-integral method which would require the computation of stresses and strains at a series of internal points around the crack for evaluation of the path-independent 
integrals, here the $J_{1}$ or SERR values are evaluated by direct differentiation of the BIE. Therefore, for the same number of elements, not only is the accuracy of the present method very high, but in terms of computational modelling and analysis, it is much more efficient.

The optimization algorithm was validated using the test cases with known analytical and or experimental solutions. Two example problems with various crack orientation angles having five different material properties are analysed. The isotropic materials were treated as if they were anisotropic. It was shown that for materials that have a plane with a lower stiffness than other planes, crack may be deflected towards such weak plane or depending on the loading condition, a crack may grow parallel to the stiffer material direction.

Here, during the incremental crack growth, it is assumed that the applied loads are large enough so that the fracture criterion holds. On the other hand, for a fibre-reinforced composite the strengths and stiffnesses in the longitudinal and transverse directions of the fibre are not the same. Therefore, by addition of appropriate constraints to the optimization algorithm, to represent the above properties, more accurate and reliable predictions of the crack growth of a composite structure subject to various loading conditions can be made.

Due to the flexibility of the present method, the future studies should cover the crack kink and propagation analysis of multiple curved cracks, and bi-material interface cracks in composites using the boundary element shape sensitivities. 


\section{References}

[1.] Snyder M.D. and Cruse T.A., "Boundary integral equation analysis of cracked anisotropic plates", Int. J. Fract 1975; 11(2): 315-28

[2.] Rice, J.R., "A path independent integral and the approximate analysis of strain concentration by notches and cracks" Journal of Applied Mechanics 1968; 35:379-386

[3.] Tafreshi, A., "Fracture Mechanics Analysis of Composite Structures Using the Boundary Element Shape Sensitivities" AIAA J 2009; 47(8), 1926-1938

[4.] Tafreshi, A., "Efficient modelling of delamination in composite cylindrical shells under axial compression", Composite Structures 2004; 64: 511-520

[5.] Tafreshi, A.,'Instability of delaminated composite cylindrical shells under combined axial compression and bending", Composite Structures 2008; 82(3): 422-433

[6.] Tafreshi, A., "Delamination Buckling of Composite Cylindrical Shells", In: Sridharan S. editor., Delamination Buckling of Composites, Cambridge, England, U.K : Woodhead 2008, Chap. 20.

[7.] Parker, A.P., "The mechanics of fracture and fatigue”, E\&F.N. Spon Ltd, 1981.

[8] Erdogan F. and Sih, G.C., "On the crack extension in plates under plane loading and transverse shear", Journal of Basic Engineering 1963; 85: 519-527

[9] Sih, G.C., "Methods of analysis and solutions of crack problems", In: Sih G.C, editor Mechanics of Fracture, Vol.1. Leiden: Noordhoff, 1973.

[10] Sih, G. C., "Some Basic Problems in Fracture Mechanics and New Concepts," Engineering Fracture Mechanics 1973; 5: 365-377.

[11] Palaniswamy, K., and W. G. Knauss, "On the Problem of Crack Extension in Brittle Solids under General Loading. In: Nemat-Nasser S., editor, Mechanics today, Vol. 4, Pergamon Press, 1978.

[12] Hussain, M.A., Pu, S.I., Underwood, J., “ Strain energy release rate for a crack under combined mode I and mode II, Fracture analysis ASTM STP 1974; 560: 2-28 
[13] Theocaris, P.S., Kardomateas, G.A., Andrianopolous, N.P., "Experimental study of the T-criterion in ductile fracture", Eng. Fracture Mech., 1982; 17(5) : 439-447

[14] Theocaris, P.S and Andrianopolous, N.P, “ The Mises elastic-plastic boundary as the core region in fracture criteria", Eng. Fracture Mech. 1982, 16(3), 425-432

[15] Sih, G.C., Paris, P.C. and Irwin, G.R.," On cracks in rectilinearly anisotropic bodies", Int. J. Fracture Mech. 1965; 1: 189-203

[16] Sih G.C., Chen E.P., Huang, S.L. and McQuillen E.J. "Material characterization on the fracture of filament-reinforced composites" J Composite Materials 1975; 9:167

[17] Arcisz, M. and Sih, G.C, "Effect of orthotropy on crack propagation", Theoretical and applied fracture mechanics, 1984, 1, 225-238

[18] Lim, W-K and Sankar, B.V., "Non-singular term effect for the inclined crack extension in anisotropic solids under uniaxial loading", Journal of Composite materials 2002, 17(36): 2031-2044

[19] Carloni, C. and Nobile, L, "Maximum circumferential stress criterion applied to orthotropic materials", Fatigue Fract Engng Mater Struct 2005, 28: 825-833

[20] Khan S.M.A. and Khraisheh M.K.,'The anisotropic R-criterion for crack initiation”, Engineering Fracture Mechanics 2008; 75: 4257-4278

[21] Chambolle A., Francfort, G.A. and Marigo, J.-J., "When and how do cracks propagate", Journal of the Mechanics and Physics of Solids 2009, 57: 1614-1622

[22] Vanderplaats G.N.,"Numerical optimization techniques for engineering design with applications", London: McGraw-Hill; 1984

[23] Cruse T A, "Boundary element analysis in computational fracture mechanics" Kluwer, Dordrecht Academic Publishers; 1988

[24] Lekhnitskii S.G.,'Theory of elasticity of an anisotropic elastic body", Holden-Day; San Fransisco, 1963 
[25] Gibson R F, "Principles of composite material mechanics", McGraw-Hill; 1994

[26] Blandford, G.E., Ingraffea, A.R. and Liggett, "Two-dimensional stress intensity factor computations using the boundary element method", International Journal for Numerical Methods in Engineering 1981; 17: 387-404

[27] Tafreshi, A., "Shape sensitivity analysis of composites in contact using the boundary element method", Engineering Analysis with boundary elements 2009; 33(2): 215-224

[28] Tafreshi A. and Fenner R.T., "Design optimization using the boundary element method", J Strain Anal 1991; 26(4): 231-241

[29] Tafreshi A., "Shape design sensitivity analysis of two-dimensional anisotropic structures using the boundary element method", Engineering Analysis with Boundary Elements 2002; 26(3), , 237-251

[30] Tafreshi A., "Optimum shape design of composite structures using the boundary element method" AIAA J 2005; 43(6): 1349-59

[31] Baek, T.H. and Rowlands R. E. "Experimental determination of stress concentrations in orthotropic composites", J. Strain Analysis 1999; 34(2), 69-81

[32] Williams, J.G and Ewing, P.D, "Fracture under complex stress-The angled crack problem”, Int. J. Fracture Mechanics 1972; 8(4): 441-446

[33] Cotterell, B., "The influence of the stress distribution at the tip of a crack", Int. J. Fract. Mech. 1966; 2(3): 526-33

[34] ABAQUS Benchmarks Manual, Version 6.8, Hibbit, Karlson and Sorenson, 2008

[35] Cotterell, B., and J. R. Rice, “Slightly Curved or Kinked Cracks," International Journal of Fracture, 1980; 16(2):155-169

[36] Pustejovsky, M.A., "Fatigue crack propagation in Titanium under general in-plane loading-I: Experiments”, Engineering Fracture Mechanics 1979; 11: 9-15 
[37] Salvadori, A., "Crack kinking in brittle materials", J. Mechanics. and Physics of Solids 2010; 58: 1835-1946

[38.] Hu, K. X., Chandra, A. and Huang, Y., "On Interacting Bridged-Crack Systems," Int. J. Solids Struc. 1994; 31(5): 599-611

[39.] Chandra, A., Hu, K. X. and Huang, Y., "A Hybrid BEM Formulation for Multiple Cracks in Orthotropic Elastic Components", Computers and Structures 1995; 56(5), 785-797

[40.] Jiang, Z. Q., Chandra, A. Huang, Y., "A Hybrid Micro-Macro BEM with Micro-Scale Inclusion-Crack Interactions", Int. J. Sol. Struct. 1996; 33(16): 2309-2329

[41.] Huang, Y., Chandra, A., Wei, X., Jiang, Z. Q. Hu, K. X., “A Numerical Calculation of Two-Dimensional Moduli for Microcracked Solids”, Int. J. Solids Struct 1996; 33(11): 15751586

[42] Rybicki E F and Kannien M F, "A finite element calculation of stress intensity factors by a modified crack closure integral", Eng Fract. Mech. 1997; 9(4): 931-8

[43] Shivakumar, K.N., Tan P.W., and Newman Jr, J.C., “ A virtual crack closure technique for calculating stress intensity factors for cracked three-dimensional bodies", Int. J. Fract. 1988; 36: 43-50 
Table 1 Elastic properties of the selected materials

\begin{tabular}{|c|c|c|c|c|c|c|c|}
\hline No. & $\begin{array}{l}\text { Elastic } \\
\text { properties }\end{array}$ & $\begin{array}{l}\mathrm{E}_{\mathrm{L}} \\
\mathrm{GPa}\end{array}$ & $\begin{array}{l}\mathrm{E}_{\mathrm{T}} \\
\mathrm{GPa}\end{array}$ & $\begin{array}{l}v_{\mathrm{LT}} \\
\mathrm{GPa}\end{array}$ & $\begin{array}{l}\mathrm{G}_{\mathrm{LT}} \\
\mathrm{GPa}\end{array}$ & \multicolumn{2}{|c|}{$\begin{array}{c}\text { Complex parameters } \\
\mu_{1}\end{array}$} \\
\hline 1 & Steel & 200.0 & 200.0 & 0.3 & 76.92 & $\mathrm{i}$ & $\mathrm{i}$ \\
\hline 2 & Titanium & 115.0 & 115.0 & 0.3 & 44.23 & $\mathrm{i}$ & $\mathrm{i}$ \\
\hline 3 & Graphite-epoxy & 144.8 & 11.7 & 0.21 & 9.66 & $0.951 \mathrm{i}$ & $3.696 \mathrm{i}$ \\
\hline 4 & $\begin{array}{l}\text { Hypothetical } \\
0.1 \leq \phi \leq 4.5 \\
E_{L}=G_{L T}\left(\varphi+2 v_{L T}+1.0\right)\end{array}$ & $\begin{array}{l}\text { For } \phi=0.1, \\
E_{L}=6.96\end{array}$ & $\mathrm{E}_{\mathrm{L}} / \phi$ & 0.03 & 6.0 & $\mathrm{i}$ & $0.3162 \mathrm{i}$ \\
\hline 5 & Ref.[31] & 18.9 & 18.9 & 0.845 & 55.6 & $-0.915+0.403 \mathrm{i}$ & $0.915+0.403 \mathrm{i}$ \\
\hline $5 b$ & & 18.9 & 18.9 & 0.845 & 20.0 & $-0.828+0.560 \mathrm{i}$ & $0.828+0.560 \mathrm{i}$ \\
\hline
\end{tabular}

Table 2 Crack kink angle of a steel plate with a centre slant crack subject to tension $\left[\mathrm{a} / \mathrm{w}=0.4, \mathrm{~h} / \mathrm{w}=2, \varphi=45^{\circ}\right]$

\begin{tabular}{|c|c|c|}
\hline Criterion & ABAQUS[30] & Present \\
\hline Max. tangential stress & $-52.41^{\circ}$ & $-54.89^{\circ}$ \\
\hline Max strain energy release rate & $-55.76^{\circ}$ & $-54.31^{\circ}$ \\
\hline $\mathrm{K}_{\mathrm{II}}=0$. & $-56.12^{\circ}$ & N/A \\
\hline
\end{tabular}


Table 3 Crack growth data for a rectangular Titaniuum plate with a central slant crack subject to tension $\left[\mathrm{a} / \mathrm{w}=0.176, \mathrm{~h} / \mathrm{w}=4, \varphi=47^{\circ}, \bar{a}=0.007 w\right]$

\begin{tabular}{|c|c|c|}
\hline $\begin{array}{l}\text { Increment } \\
\text { No. }\end{array}$ & $\begin{array}{c}\varphi[\text { degrees] } \\
\text { (with respect to the } \mathrm{x} \text { axis) }\end{array}$ & $\begin{array}{c}\Theta_{0}[\text { degrees }] \\
\text { (With respect to the previous crack } \\
\text { surface) }\end{array}$ \\
\hline 1 & -9.12 & -56.12 \\
\hline 2 & -7.69 & 1.42 \\
\hline 3 & 0.56 & 8.26 \\
\hline 4 & -7.93 & -8.49 \\
\hline 5 & -7.46 & 0.47 \\
\hline 6 & -7.08 & 0.38 \\
\hline 7 & -6.86 & 0.21 \\
\hline 8 & -6.70 & 0.16 \\
\hline 9 & -6.65 & 0.04 \\
\hline 10 & -6.59 & 0.05 \\
\hline 11 & -6.33 & 0.26 \\
\hline 12 & -6.22 & 0.11 \\
\hline 13 & -6.20 & 0.02 \\
\hline 14 & -6.08 & 0.11 \\
\hline 15 & -5.70 & 0.38 \\
\hline 16 & -5.61 & 0.08 \\
\hline 17 & -5.34 & 0.26 \\
\hline 18 & -5.31 & 0.02 \\
\hline 19 & -5.11 & 0.20 \\
\hline 20 & -4.92 & 0.19 \\
\hline
\end{tabular}




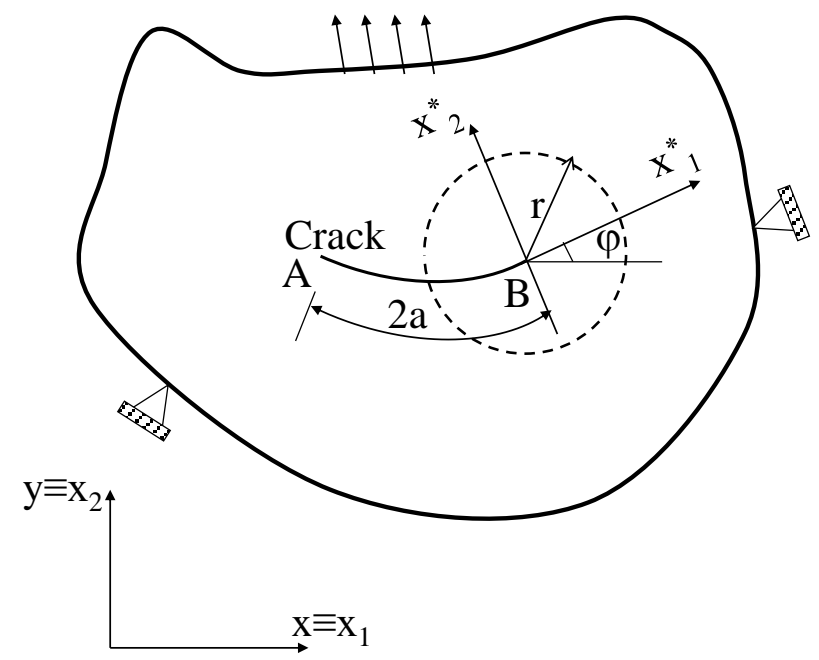

Fig. 1 General crack body under mixed-mode loading 


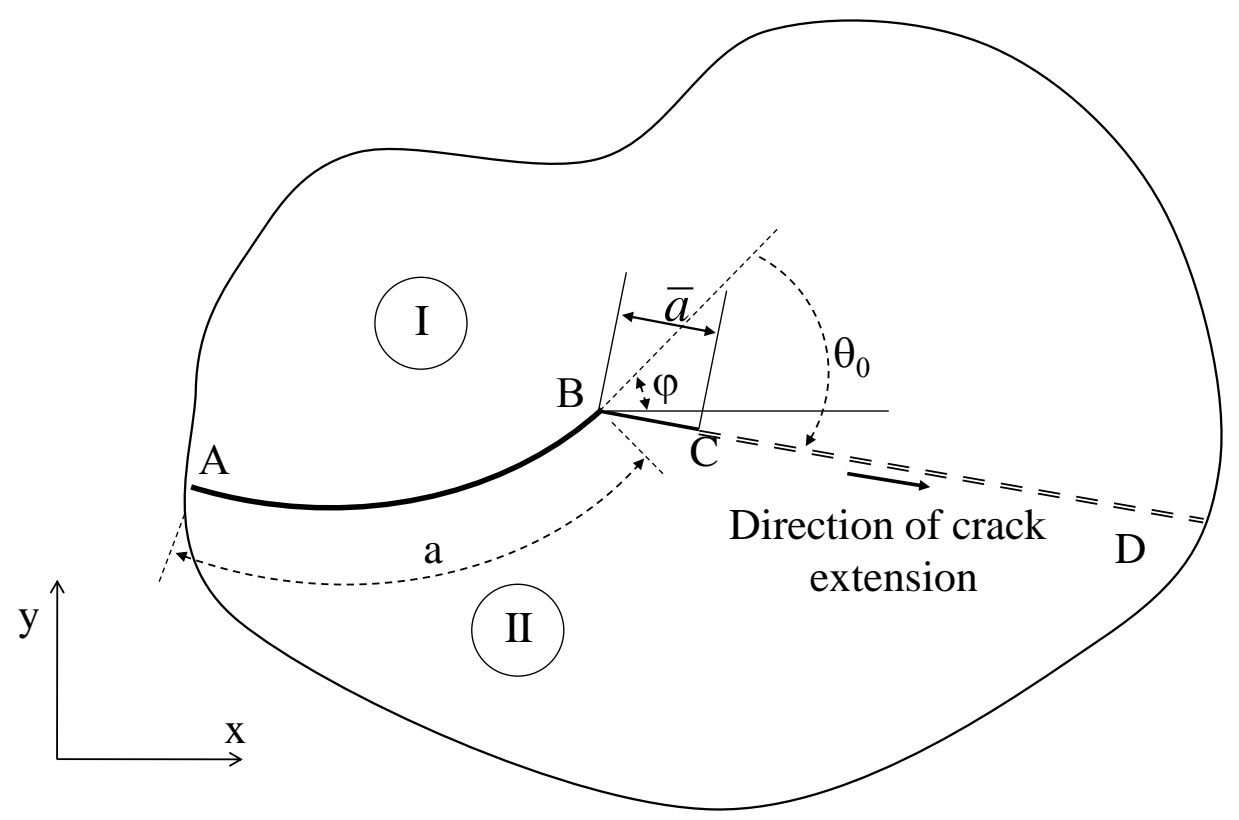

Fig. 2a Initiation of an infinitesimally small kink $B C$ from the main crack $A B$

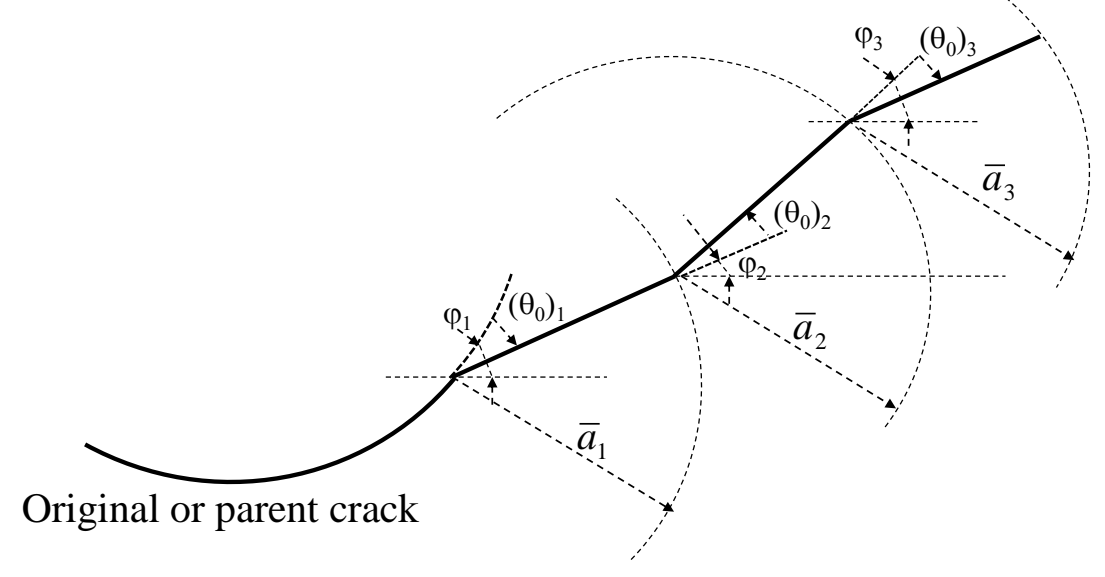

Fig. 2b Crack propagation path 


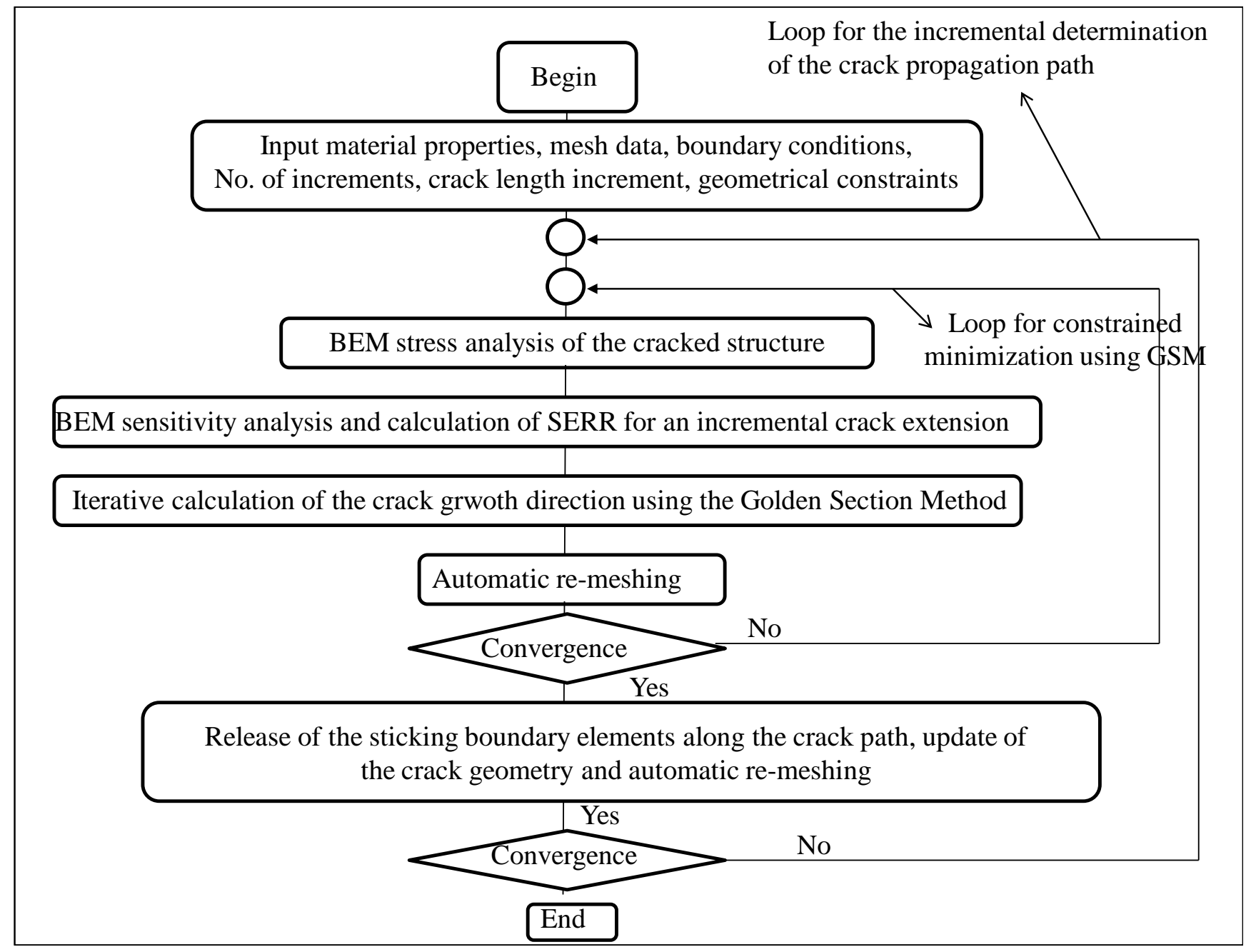

Fig. 3 Flow diagram for the simulation of crack growth 


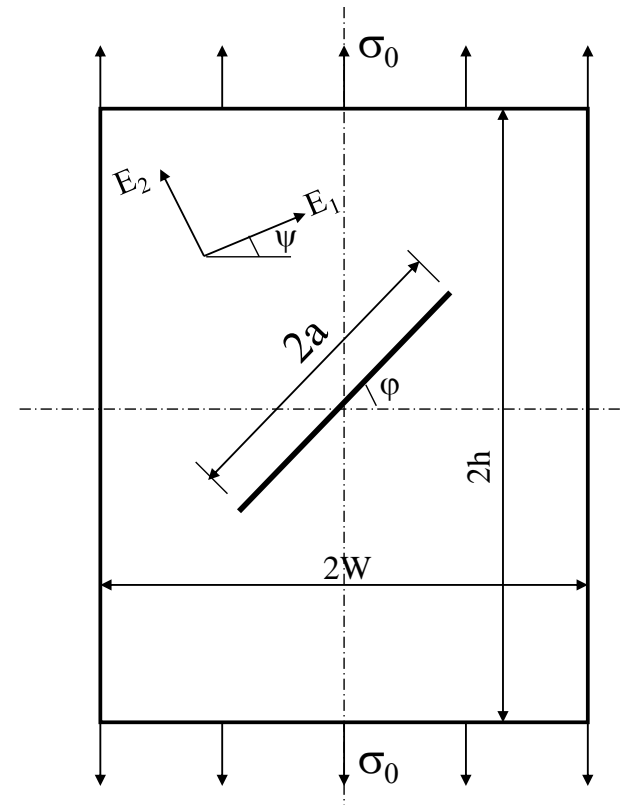

Figure 4 Central slant crack in a rectangular plate subject to tension

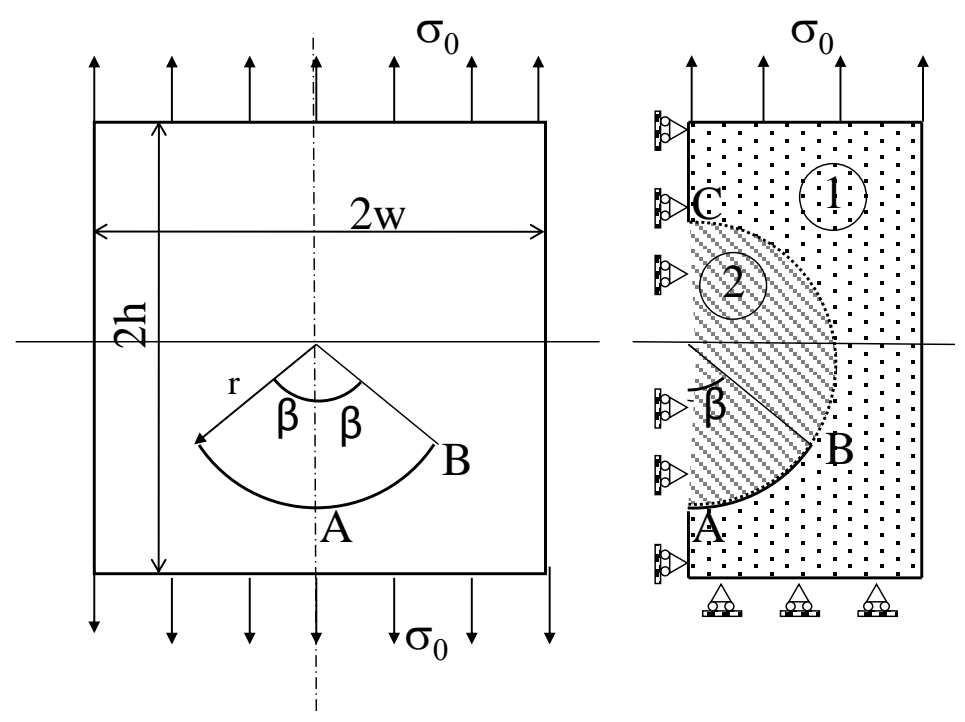

Fig. 5 A circular arc crack in an infinite plate subject to tension 


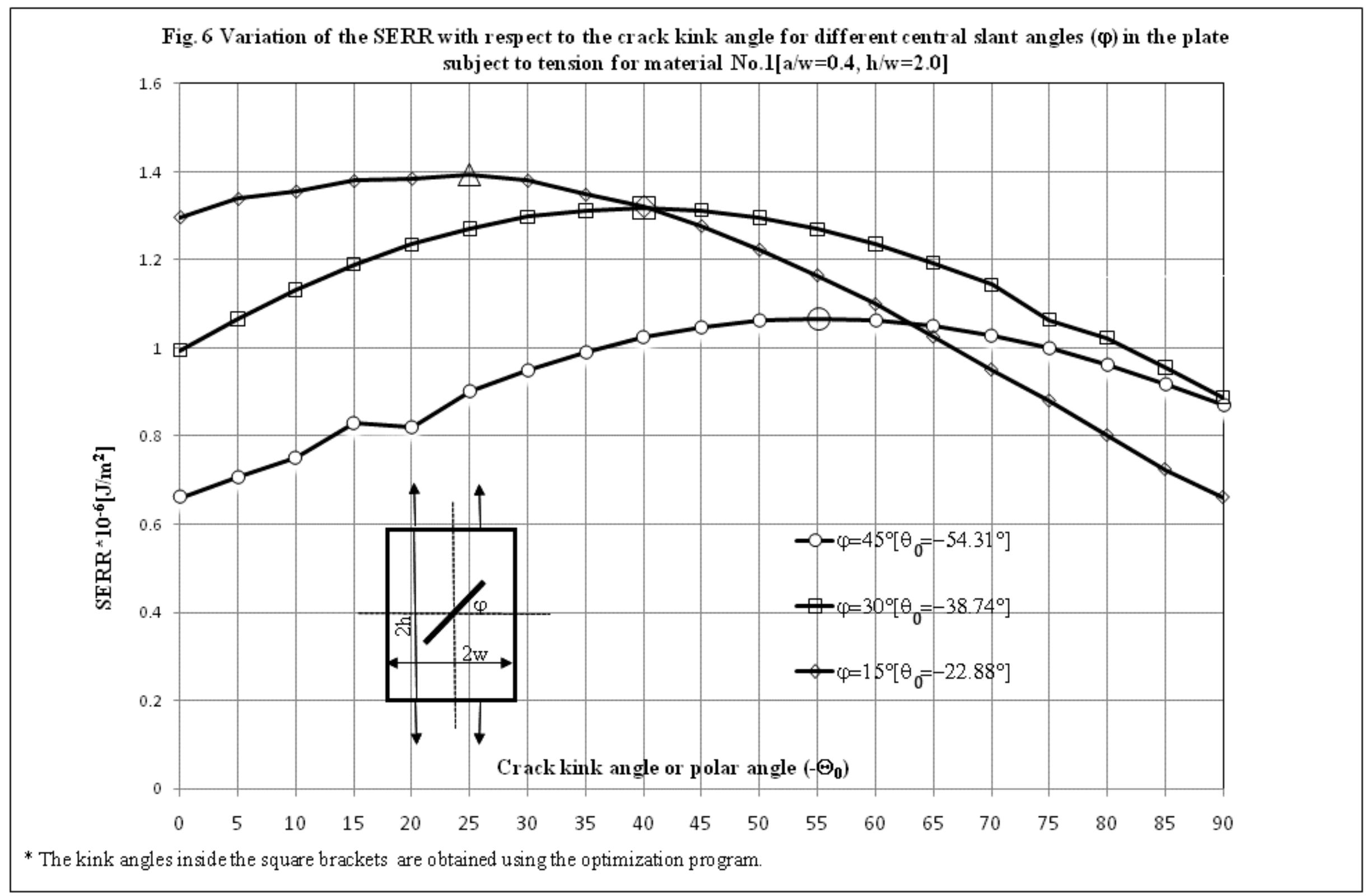




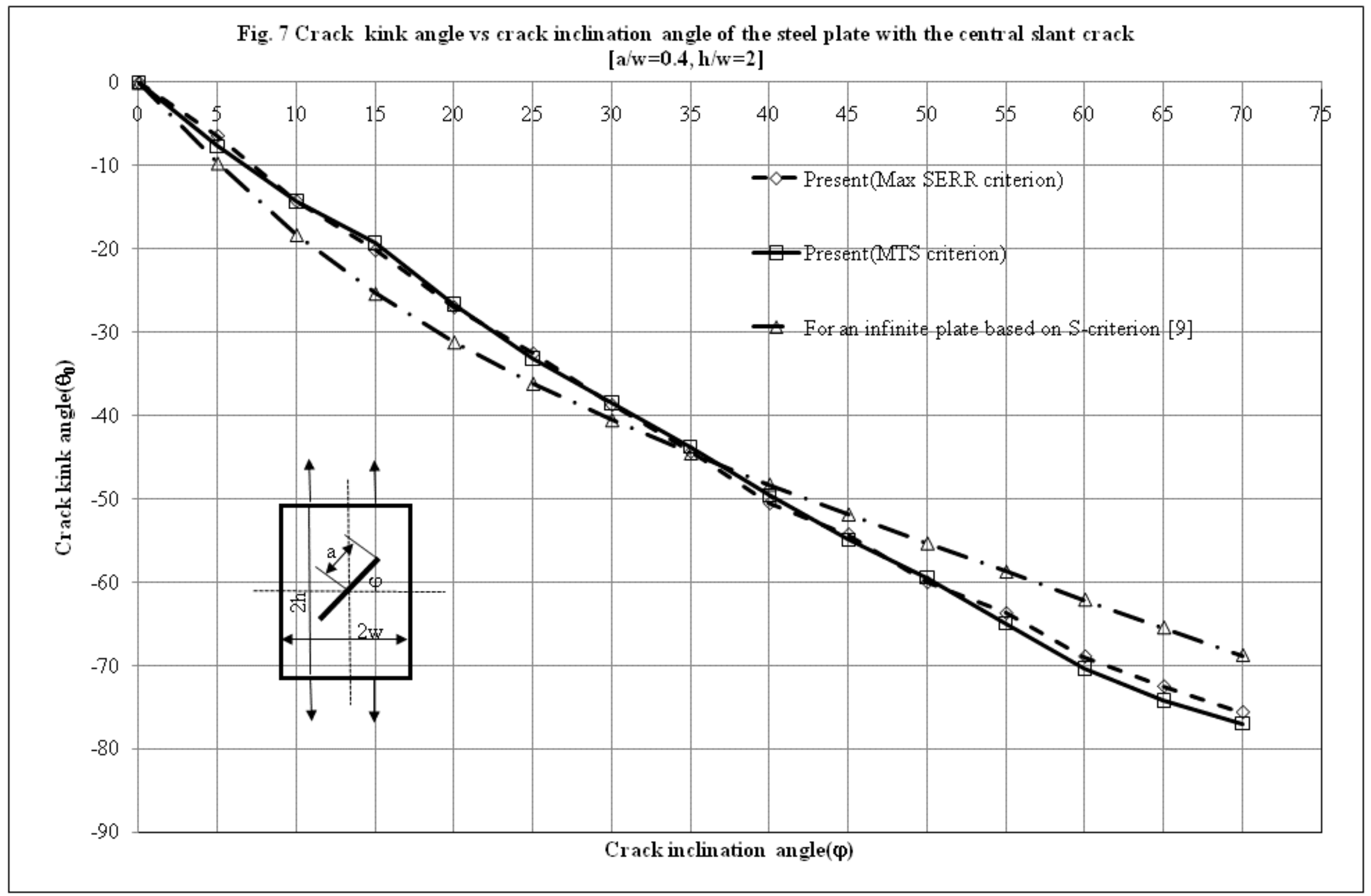




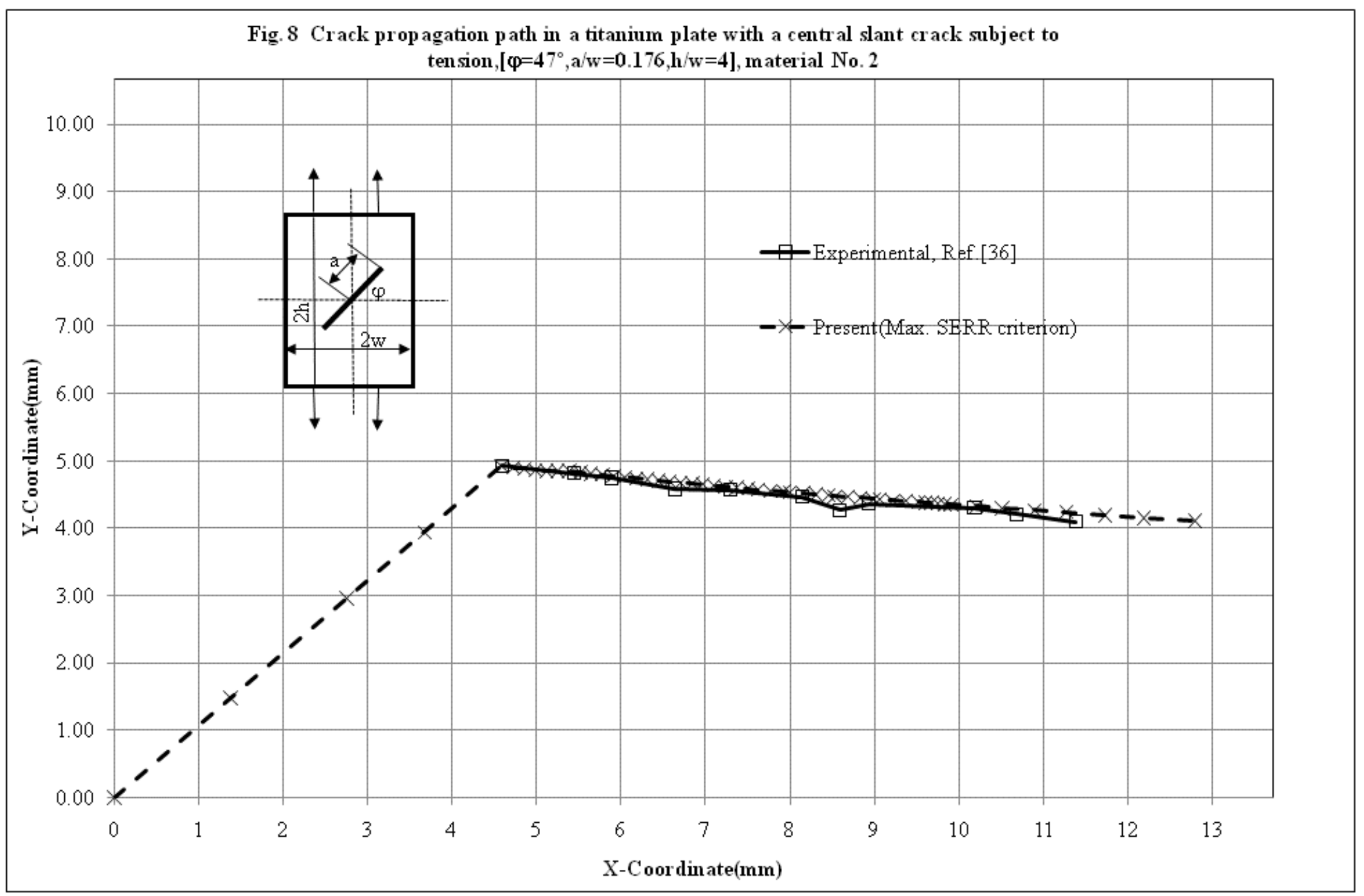




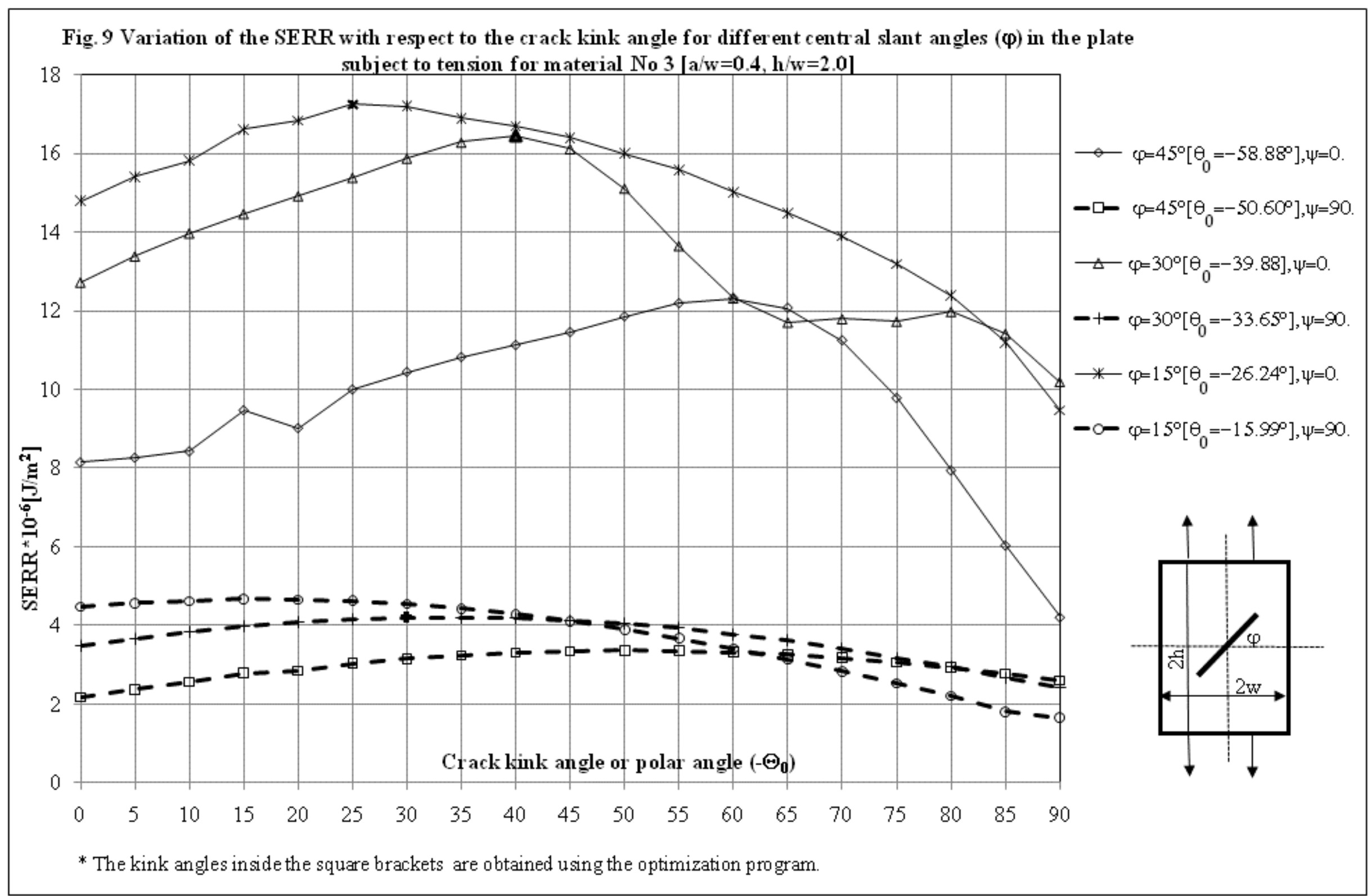




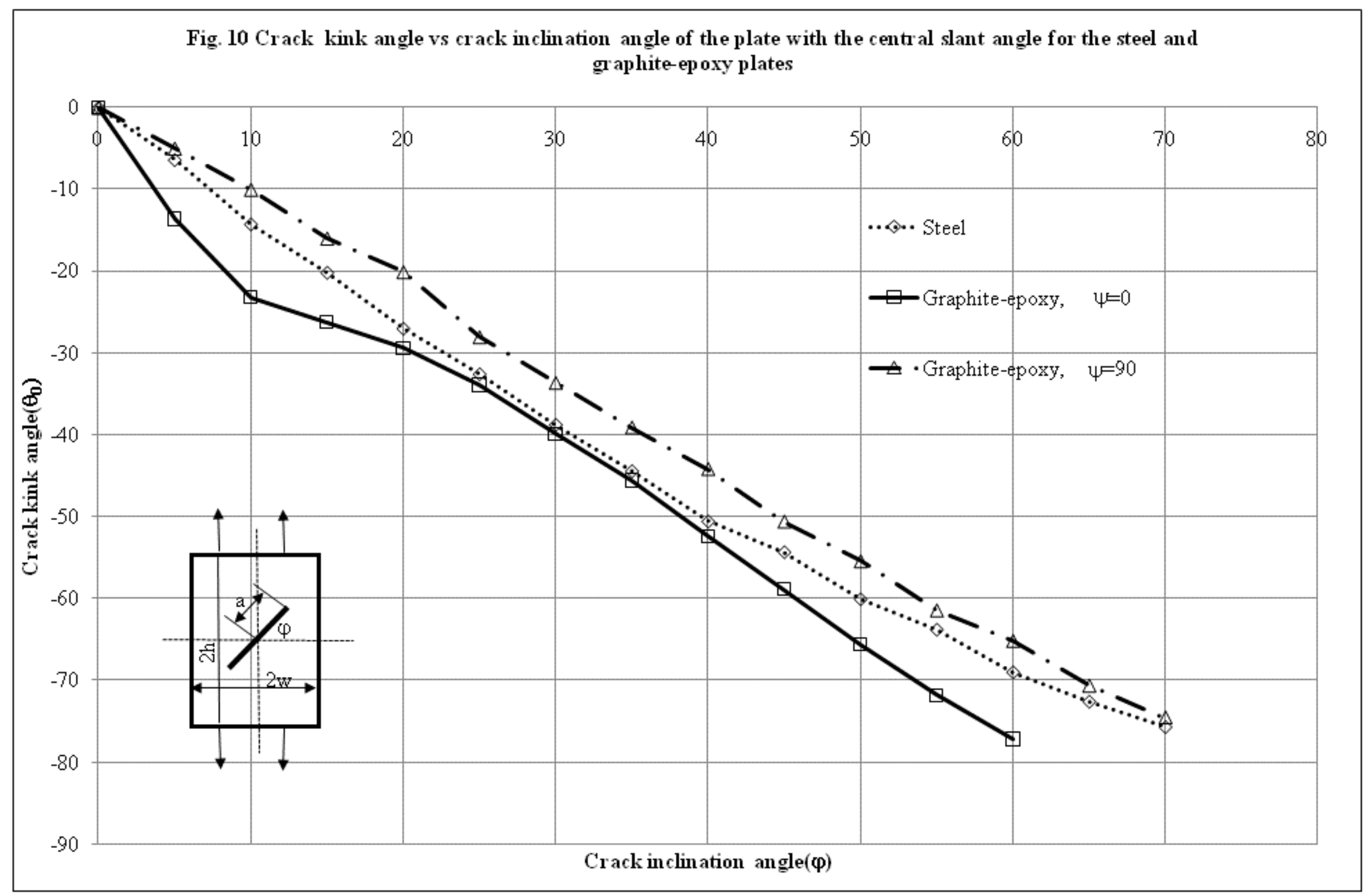




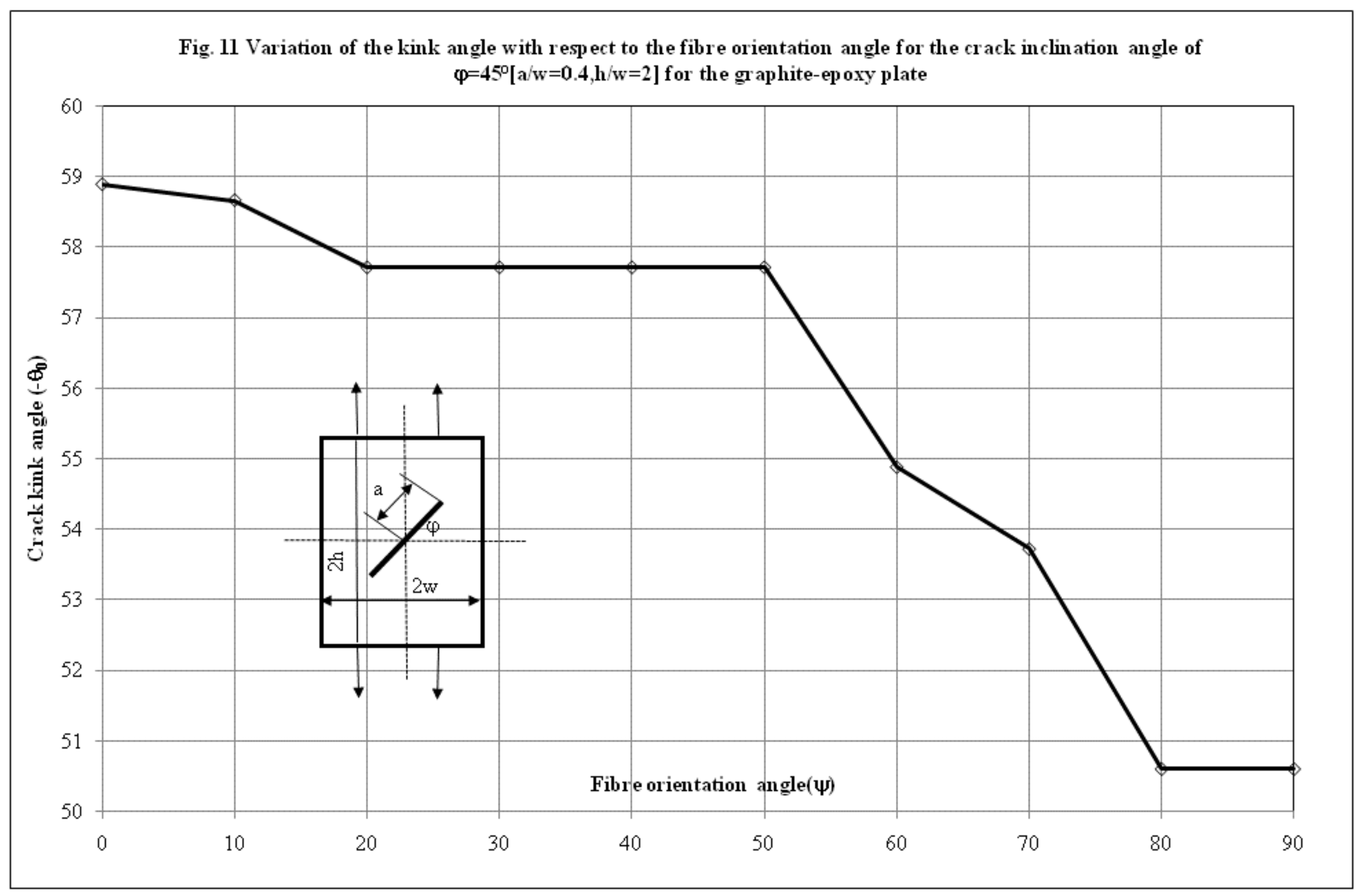




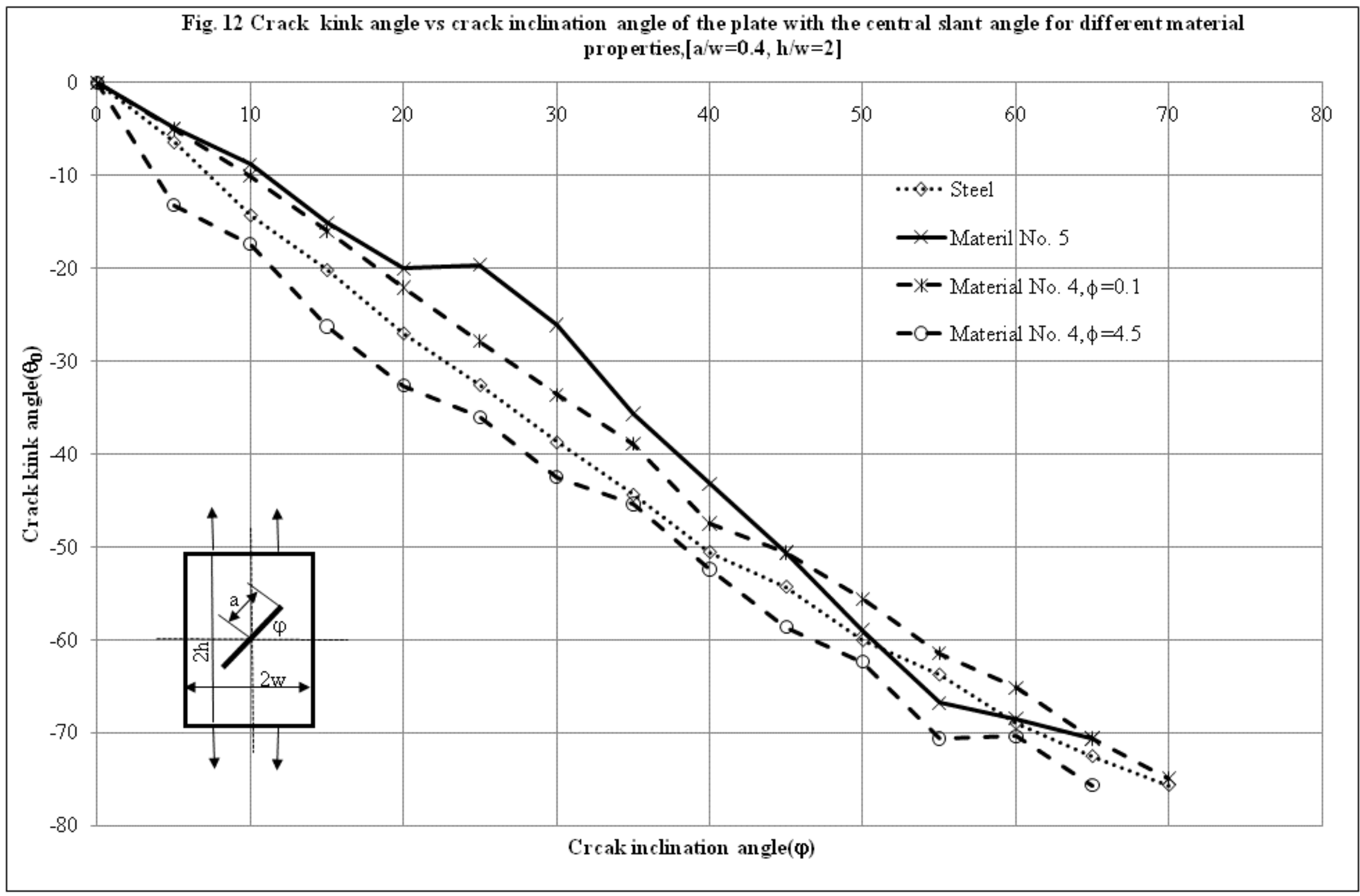




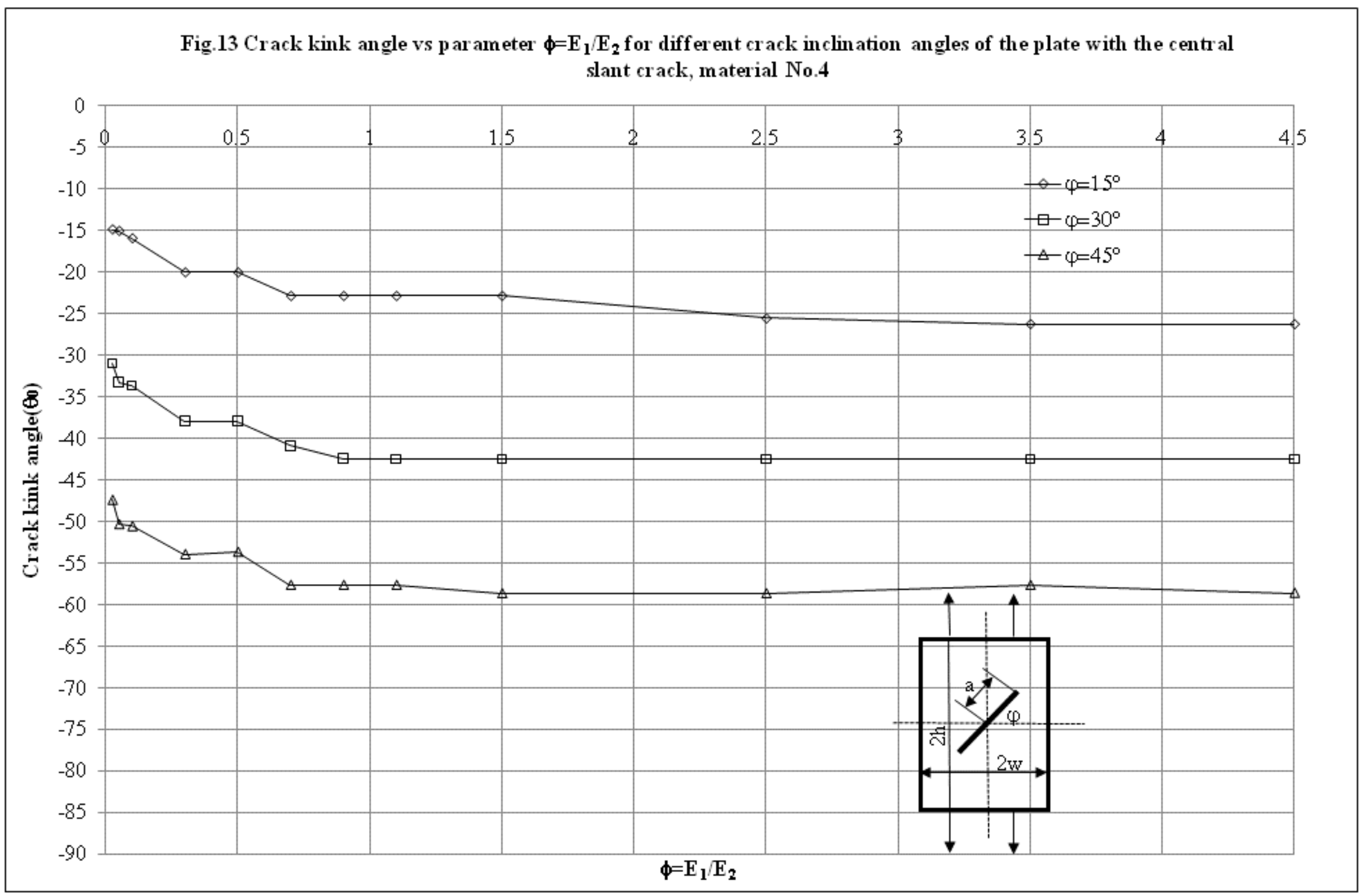




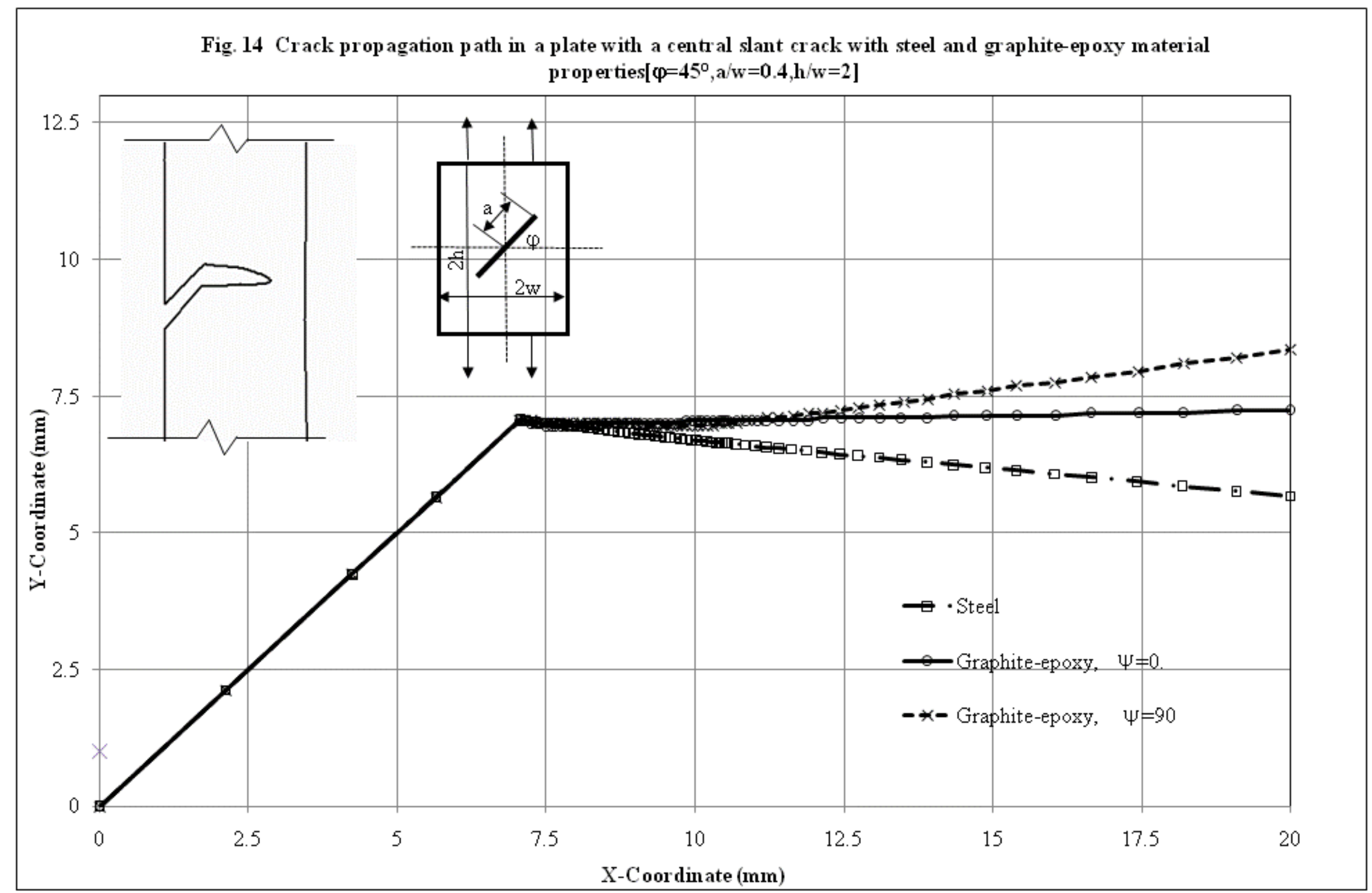




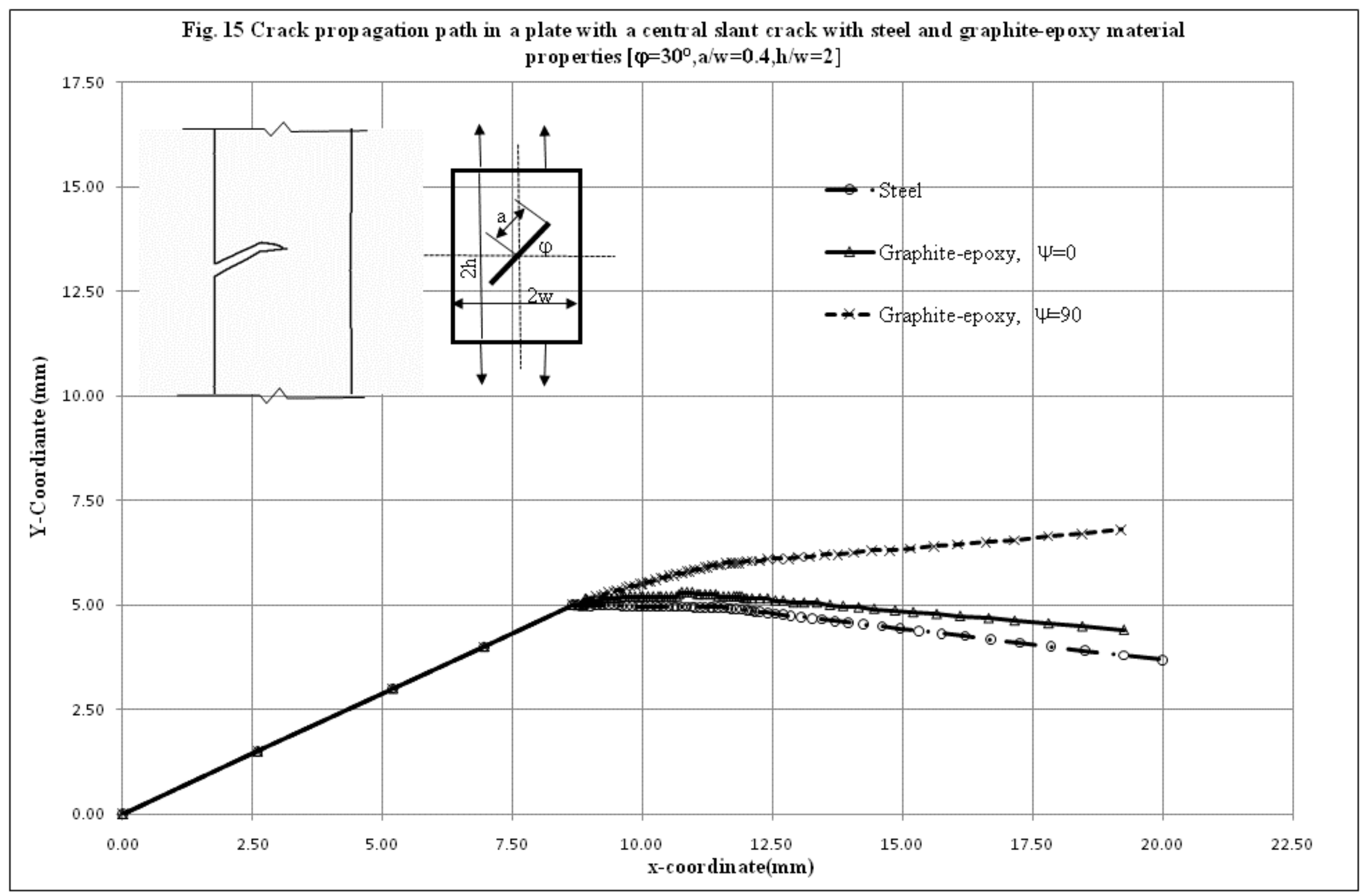




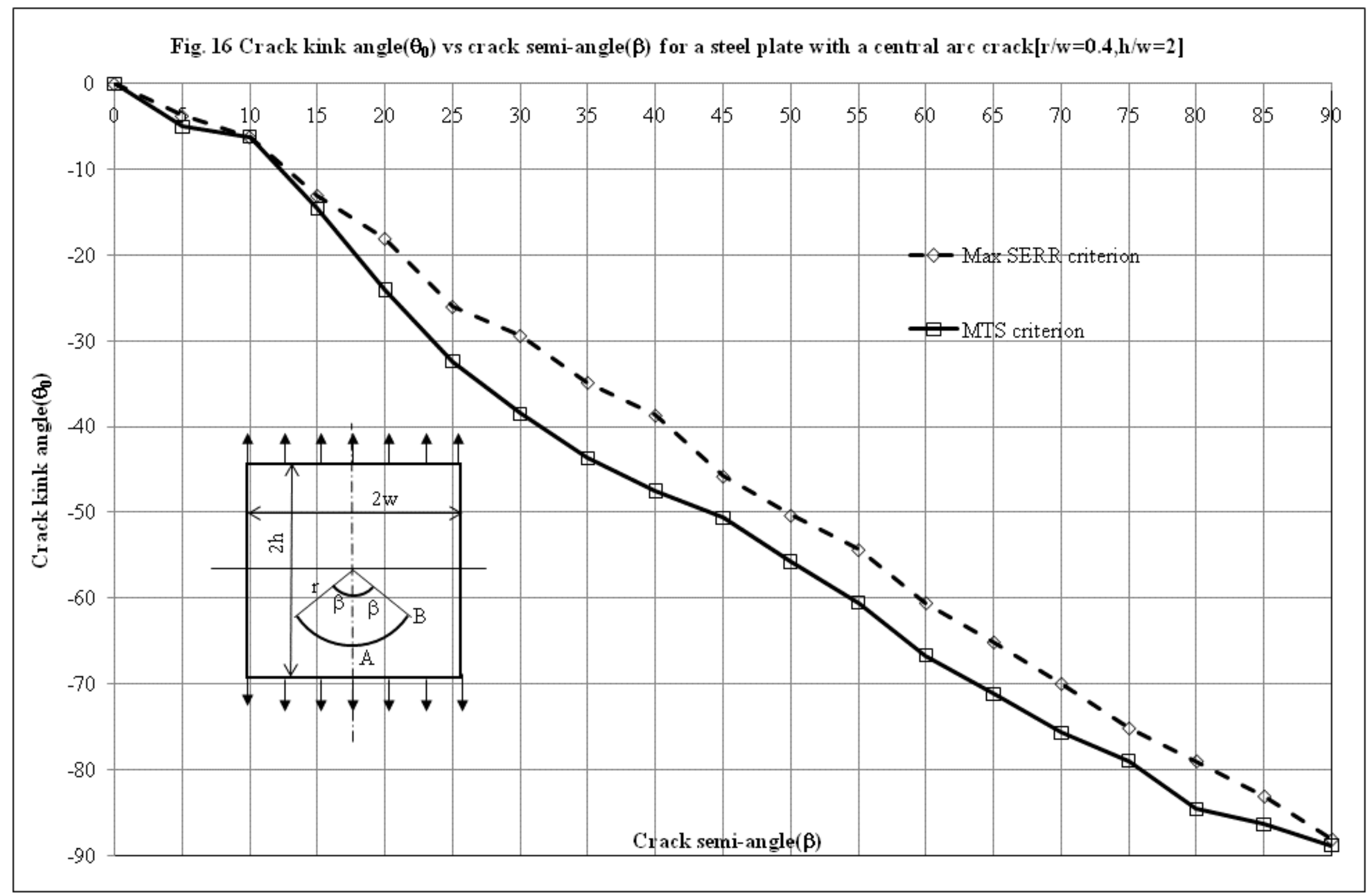




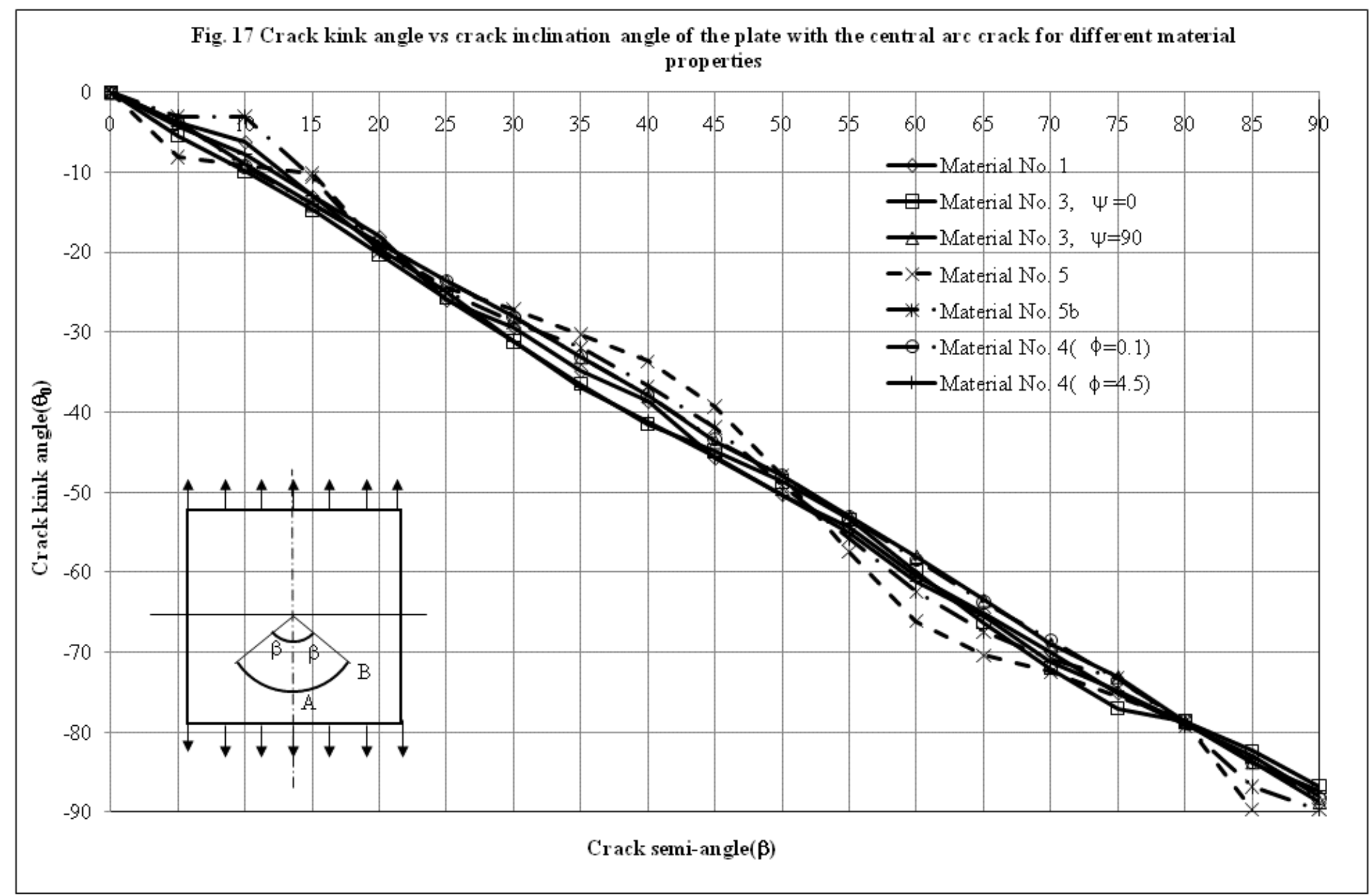




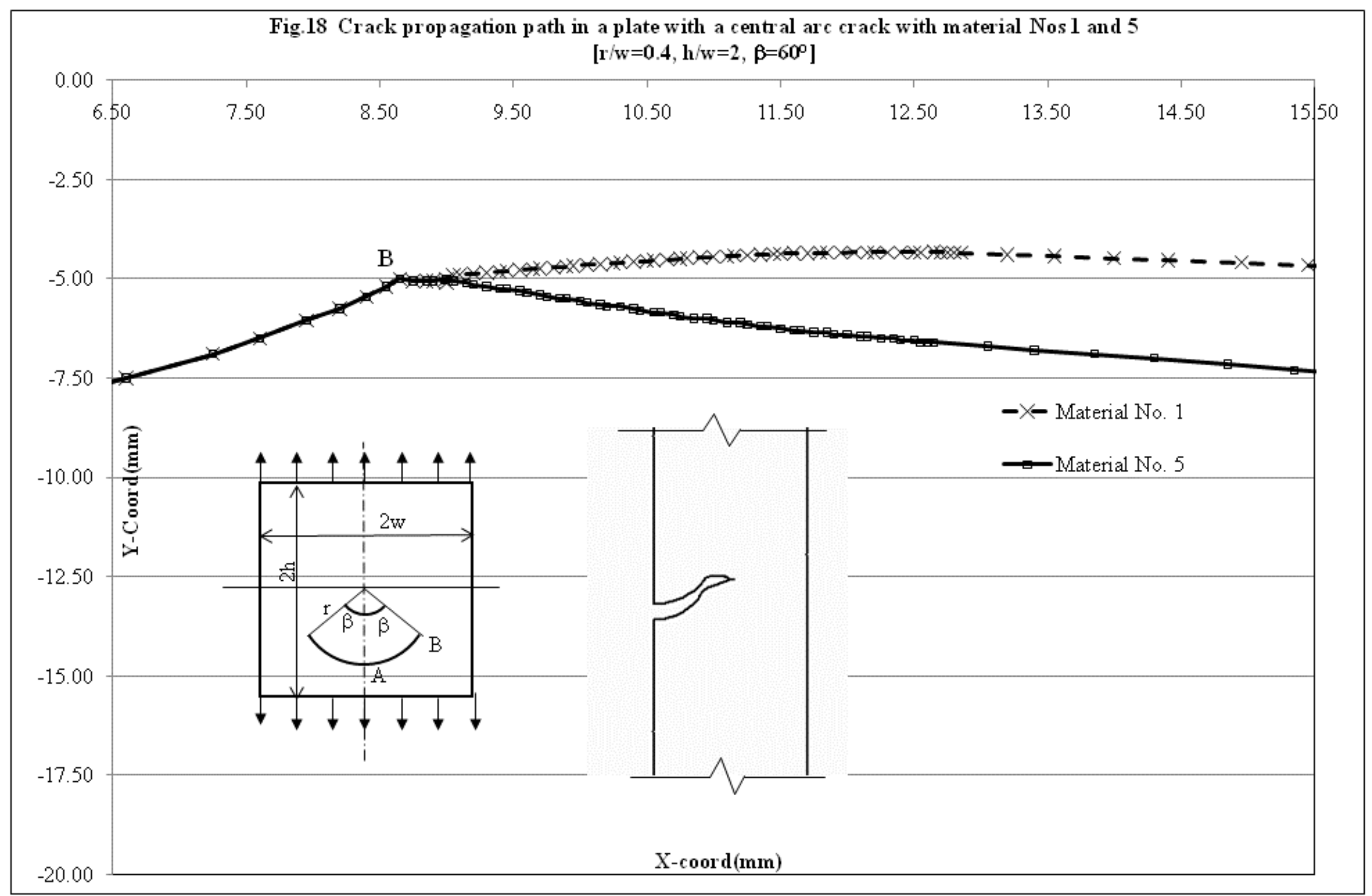

